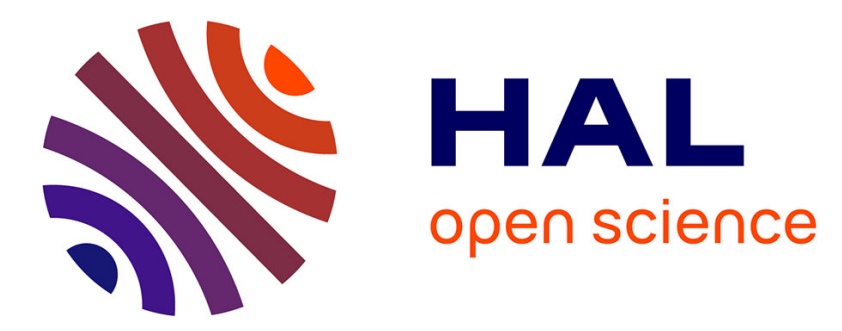

\title{
An Autonomous Self-Optimizing Flow Reactor for the Synthesis of Natural Product Carpanone
}

\author{
Daniel Cortés-Borda, Eric Wimmer, Boris Gouilleux, Elvina Barré, Nicolas \\ Oger, Lubna Goulamaly, Louis Peault, Benoit Charrier, Charlotte Truchet, \\ Patrick Giraudeau, et al.
}

\section{To cite this version:}

Daniel Cortés-Borda, Eric Wimmer, Boris Gouilleux, Elvina Barré, Nicolas Oger, et al.. An Autonomous Self-Optimizing Flow Reactor for the Synthesis of Natural Product Carpanone. Journal of Organic Chemistry, 2018, 83 (23), pp.14286-14299. 10.1021/acs.joc.8b01821 . hal-01980485

\section{HAL Id: hal-01980485 \\ https://hal.science/hal-01980485}

Submitted on 19 Feb 2021

HAL is a multi-disciplinary open access archive for the deposit and dissemination of scientific research documents, whether they are published or not. The documents may come from teaching and research institutions in France or abroad, or from public or private research centers.
L'archive ouverte pluridisciplinaire HAL, est destinée au dépôt et à la diffusion de documents scientifiques de niveau recherche, publiés ou non, émanant des établissements d'enseignement et de recherche français ou étrangers, des laboratoires publics ou privés. 


\section{An Autonomous Self-Optimizing Flow Reactor for the Synthesis of Natural Product Carpanone}

Daniel Cortés-Borda, ${ }^{\ddagger \pm}$ Eric Wimmer, ${ }^{\ddagger \pm}$ Boris Gouilleux,${ }^{\ddagger}$ Elvina Barré, ${ }^{\ddagger}$ Nicolas Oger, ${ }^{\ddagger}$ Lubna Goulamaly, ${ }^{\dagger}$ Louis Peault, ${ }^{*}$ Benoît Charrier, ${ }^{\star}$ Charlotte Truchet ${ }^{\dagger}$ Patrick Giraudeau, ${ }^{\ddagger}{ }^{\ddagger}$ Mireia Rodriguez-Zubiri, ${ }^{\star}$ Erwan Le Grognec, ${ }^{\dagger}$ François-Xavier Felpin**\$,

‡Université de Nantes, UFR des Sciences et des Techniques, CNRS UMR 6230, CEISAM, 2 rue de la Houssinière, 44322 Nantes Cedex 3, France

${ }^{\dagger}$ Université de Nantes, UFR des Sciences et des Techniques, CNRS UMR 6241, LINA, 2 rue de la Houssinière, 44322 Nantes Cedex 3, France

${ }^{\S}$ Institut Universitaire de France, 1 rue Descartes, 75231 Paris Cedex 05, France

${ }^{ \pm}$These authors contributed equally to the project

\section{ABSTRACT GRAPHIC}

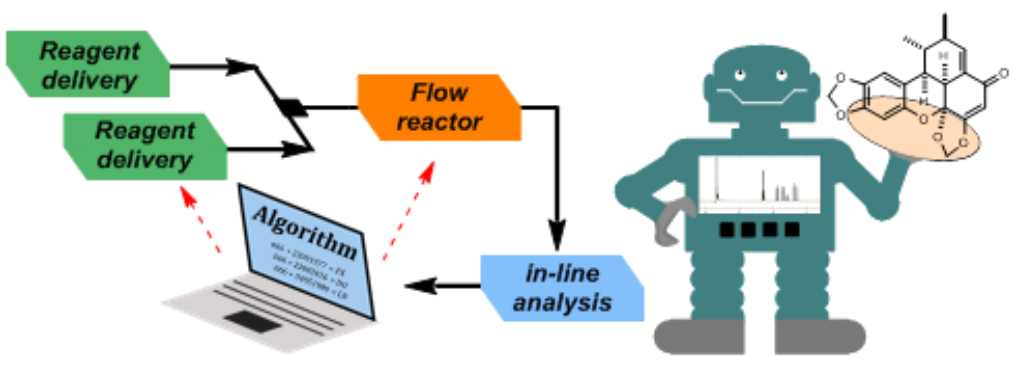

\section{ABSTRACT}

A modular autonomous flow reactor combining monitoring technologies with a feedback algorithm is presented for the synthesis of the natural product carpanone. The autonomous self-optimizing system, controlled via MATLAB ${ }^{\circledR}$, was designed as a flexible platform enabling an adaptation of the experimental setup to the specificity of the chemical transformation to be optimized. The reaction monitoring uses either on-line high pressure liquid chromatography (HPLC) or in-line benchtop nuclear magnetic resonance (NMR) 
spectroscopy. The custom-made optimization algorithm derived from the Nelder-Mead and golden section search methods performs constrained optimizations of black-box functions in a multi-dimensional search domain, thereby, assuming no a priori knowledge of the chemical reactions. This autonomous self-optimizing system allowed fast and efficient optimizations of the chemical steps leading to carpanone. This contribution is the first example of a multi-step synthesis where all discrete steps were optimized with an autonomous flow reactor.

\section{INTRODUCTION}

These last thirty years, biology massively imported automated technologies and nowadays, the use of robots to handle thousands of samples is part of the daily routine of biologists. By contrast, synthetic chemists, have been traditionally more resistant to the use of new technologies and many chemical laboratories still use traditional glassware without any assistance of modern automation, though early examples of automation were reported many years ago. ${ }^{1}$ The main reason for the underdevelopment of automated processes in chemical laboratories is certainly related to the difficult handling of sensitive or even hazardous reagents in a wide variety of conditions. Another major, but more questionable, reason is that synthetic chemists have long regarded the success of complex transformations based on the chemist's intuition without technological assistance like climbing Everest without Sherpa and oxygen assistance: a heroically and noble prowess. However, this situation is slowly changing and chemistry is progressively catching up with biology through the development of various automated reactors equipped with digital interfaces, camera and robots. ${ }^{2-11}$

In the long list of tasks assigned to synthetic chemists within scientific projects, the optimization stage is particularly well adapted to get assistance from automated technologies since it is highly time consuming and mostly based on reiterations. Yet, traditional onevariable-at-a-time optimizations, based on the know-how of chemists, fail to explain interactions between reaction parameters and do not follow rational pathways, precluding any efficient automation. With the use of design of experiment (DoE) methods, chemists can introduce automated technologies to screen a set of predetermined experimental conditions. However, these methods are usually expensive with regard to the high number of experiments required to locate a satisfactory result. Recent developments for substituting DoE methods by evolutionary algorithms associated to flow reactors opened a new way to address the optimization stage. ${ }^{12}$ These studies culminated with the emergence of self-optimizing flow reactors as powerful automated devices to assist the decision-making process of chemists 
involved in the optimization of chemical reactions. ${ }^{13-17}$ This groundbreaking technology associates flow reactors with process control instrumentation, in-line/on-line analysis techniques and optimization algorithms in a single autonomous device working without human intervention after initialization. Flow reactors are particularly well suited and far better adapted than traditional discontinuous tank reactors to optimize chemical reactions in an autonomous manner since they benefit from a higher reproducibility, better heat and mass transfer, reduced reaction time, and much easier automation. ${ }^{18-23}$ In pioneering studies, the group of deMello paved the way of this research line through the synthesis of CdSe nanoparticles with an autonomous flow reactor. ${ }^{24-25}$ Later, the technology was further improved and exemplified by Jensen, ${ }^{26-31}$ Poliakoff, ${ }^{32-35}$ Lapkin, ${ }^{36-37}$ Cronin, ${ }^{38}$ Ley, ${ }^{39}$ Rueping $^{40}$ and Bourne ${ }^{41-44}$ groups. The self-optimizing systems proposed by these groups mainly differs from both the reaction monitoring and the optimization algorithm. However, common to all these studies is that each system has never been challenged and exemplified for a multi-step synthesis where a modular flow device and robust algorithm are required. In the frame of our interest in flow chemistry, ${ }^{45-48}$ we describe the first use of a modular selfoptimizing flow device, integrating a powerful custom-made optimization algorithm, in the context of a multi-step synthesis for the total synthesis of carpanone 1. This natural product, isolated from the bark of the carpano tree as a racemate, is the most representative member of a family of lignanes belonging in a group of naturally occurring benzoxanthenones also containing polemannone A-C and sauchinone (Figure 1). 
<smiles></smiles>

1, Carpanone<smiles>COC1=C2OCOC23OCOc2c(OC)c4oc(=O)c2cc4[C@H]2C3C(=CC(C)[C@H]2C)C1=O</smiles>

3, Polemannone B<smiles>COC1=C2OCO[C@]23Oc2c(cc(OC)c(OC)c2OC)[C@@H]2[C@H]3C(=CC(C)[C@H]2C)C(=O)C1=O</smiles>

2, Polemannone A

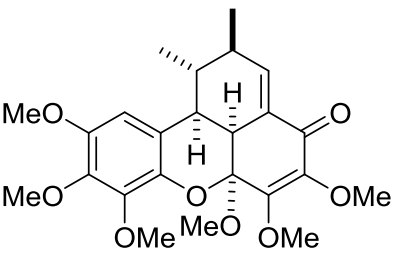

4, Polemannone C

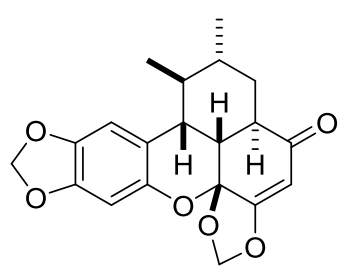

5, Sauchinone

FIGURE 1. Natural lignans sharing a benzoxanthenone structure.

With its highly oxygenated hexacyclic structure containing six contiguous stereogenic centers, carpanone $\mathbf{1}$ is an ideal benchmark target to introduce automated technologies in multi-step synthesis. The objective of this work is more on the development of autonomous technologies in multi-step synthesis rather than on the development of an original synthetic route. Therefore, we roughly followed the synthetic strategies reported in batch by Chapman, ${ }^{49}$ Ley $^{50}$ and Beifuss ${ }^{51}$ groups and we profoundly modified experimental conditions to flow requirements (Scheme 1). Adapting or transferring experimental conditions of batch reactions to a flow regime is not a trivial task as the perfect solubility of reagents, catalysts and additives must be carefully monitored, otherwise, clogging issues prevent the flow reactor to properly work. Chemical transformations having very low kinetics are also difficult to run under a flow regime, though high pressure/temperature conditions can, in certain cases, solve this issue. ${ }^{52}$ The general strategy starts with the allylation of commercially available sesamol $\mathbf{6}$ followed by a [3,3]-Claisen rearrangement to furnish allyl sesamol $\mathbf{8}$. After isomerization of the double bond, a beautiful oxidative dimerization of desmethoxycarpacin 9 furnishes carpanone 1. For the sake of comparison, readers could also be interested by alternative routes, all executed in a batch mode. ${ }^{53-55}$ 

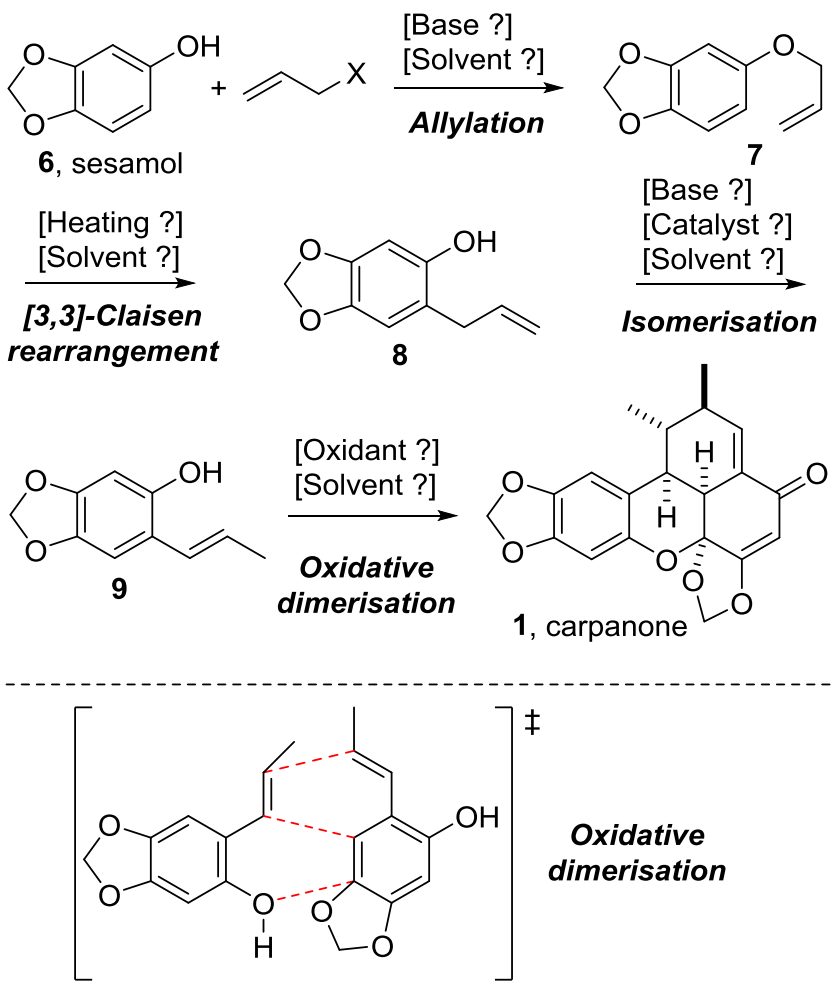

SCHEME 1. General synthetic route for the synthesis of carpanone 1 in flow

\section{RESULTS AND DISCUSSION}

Requirements for the self-optimizing flow reactor. Our self-optimizing approach integrates a flow reactor with automated units (pumps, sample handler, oven, valve, back pressure regulator and fraction collector) and in-line or on-line monitoring ${ }^{56}$ into a single device under the control of a real-time optimization algorithm. The self-optimizing device is driven by a black-box optimization algorithm and an automated experimental sequence, both in-house developed and fully coded in MATLAB ${ }^{\circledR}$. The optimization algorithm starts by proposing the experimental conditions. Then, the automated experimental sequence sets the conditions in the connected units. Once the reaction is finished, the experimental sequence launches the reaction monitoring and finally, the experimental sequence feeds back the reaction results to the optimization algorithm in order to propose new experimental conditions. This process is repeated iteratively until eventually converging on an optimum without any human intervention.

In this work, we used either on-line HPLC or in-line NMR monitoring; the selection of the analytical tool depends on several parameters including the concentration of reagents and the ability to distinguish the targeted compound with respect to the starting material and potential side-products. 
On the one hand, on-line HPLC analysis with a UV detection features a $(i)$ high sensitivity allowing to work in a wide variety of concentrations, (ii) good flexibility for the separation of compounds through the use of various chromatography columns and (iii) facile integration in the experimental setup. However, HPLC does not provide true real-time analysis and structural elucidation is not possible.

On the other hand, NMR spectroscopy has the great advantage of being non-specific, nondestructive and yields structural and quantitative insights. However, high-field NMR relying on an expensive and bulky hardware is usually not regarded as a routine processing analytical tool within a flow-chemistry platform. The emergence of performant benchtop NMR spectrometers provides a relevant alternative. ${ }^{57-58}$ Such low-field spectrometers - based on compact and cryogen-free magnets - operate directly under a fume hood and are compatible with in-line analysis applications in a non-deuterated solvent. ${ }^{47,}{ }^{59}$ Moreover, this technology is experiencing continuous improvements and the recent implementation of gradient coils has enabled the development of modern and efficient NMR methods such as advanced solvent suppression methods ${ }^{60}$ or Ultrafast 2D NMR for quasi real-time analysis. ${ }^{61}$ While the wealth of information delivered by NMR is arguably a net advantage with respect to liquid chromatography for self-optimizing flow devices, the inherent low magnetic field (typically 1 $\mathrm{T}$ ) is inevitably plagued by a significant lower sensitivity and resolution. In practice, we restricted benchtop NMR monitoring for concentrations above $0.3 \mathrm{M}$ in starting materials, with NMR experiment durations of $c a .1 \mathrm{~min}$. The strengths and weaknesses discussed above highlight the real complementarity between HPLC and benchtop NMR so that one can choose the more relevant technique depending on the reaction characteristics.

Optimization algorithm. The lack of explicit mathematical expressions modelling the objective function (e.g., reaction yield, productivity, cost, etc.) as function of the experimental variables in most cases precludes applying complete optimization methods in chemistry. Thus, optimizing chemical reactions without a priori reaction and gradient information is not trivial and chemists resort to heuristics and/or DoE methods to characterize the objective function, under unneglectable economic and time constraints. Our strategy to succeed in such great challenge consists in using the Nelder-Mead method, ${ }^{62}$ a gradient-free method (belonging to the category of direct search methods), that treats the chemical reaction as a black-box in which input variables (e.g., temperature, residence time, etc.) are transformed into an output variable to be optimized (e.g., yield, productivity, etc.). The Nelder-Mead method explores the objective function's domain with $n$-dimensional simplexes (convex polytopes with $n+1$ vertices), where $n$ is the optimization problem dimension (the number of 
input variables) and each vertex represents an experiment. This method ranks the $n+l$ vertices of a simplex according to their objective function values and replaces the worst of them with a new (always better) vertex, giving rise to a new simplex. A systematic repetition of this process ultimately leads to a point corresponding to a value which cannot be improved, namely a local optimum.

The initial simplex is created by an initial point $X_{0}$ plus $n$ points obtained by increasing (or decreasing) one variable at a time by a given value $d$. Unlike DoE, the one-variable-at-a-time approach is only used to create the initial simplex. After the first $n+1$ experiments, the size and shape of the exploratory simplex changes and hence modifies multiple variables at a time, thereby increasing the diversification of the algorithm, hence, presumably, the probability of finding a local optimum with a reduced number of experiments.

In this work we used a profoundly modified version of the Nelder-Mead method that demonstrated to successfully optimize flow reactions in a comfortably afforded number of experiments by assuming a smooth surface of the (not necessarily unimodal) objective function. ${ }^{48}$ The modified version of the Nelder-Mead method is adapted to $(i)$ handle linear constraints imposed by the upper/lower bounds of variables and by linear combinations of the input variables, (ii) modify the dimensionality of the optimization problem (ii) stop by multiple stopping criteria lowering the number of experiments and (iii) diversify the search and escape from local optima. Additionally, in this work we included the golden section search $^{63}$ to handle 1-dimension boundary searches which the Nelder-Mead method fails to tackle. Moreover, all optimizations carried out in this work were limited to a maximum of 30 experiments after which, the algorithm proposes to stop the search if the operator considers that a satisfactory optimum has been found. Otherwise, the operator can decide to continue the autonomous optimization until the algorithm reaches another stopping criterion.

Synthesis of carpanone using an autonomous self-optimizing flow reactor. The synthesis of carpanone $\mathbf{1}$ started with the allylation of commercially available sesamol $\mathbf{6}$. In batch conditions, sesamol $\mathbf{6}$ was smoothly allylated with allyl bromide in acetone, using $\mathrm{K}_{2} \mathrm{CO}_{3}$ as a base. ${ }^{51}$ While these conditions provided the corresponding allylated compound 7 in good yield ( $>80 \%$ ), they proved to be unsuited for flow conditions since both $\mathrm{K}_{2} \mathrm{CO}_{3}$ used as a base and $\mathrm{KBr}$ produced as by-product were insoluble in acetone. In preliminary flow experiments, we envisaged the immobilization of either $\mathrm{K}_{2} \mathrm{CO}_{3}$ or Amberlyst ${ }^{\circledR} \mathrm{A} 26$, a resin in the hydroxide form, in an Omnifit ${ }^{\circledR}$-type glass column. However, we rapidly realized that this approach was plagued by several issues since the immobilized base could not be easily regenerated in-line without human intervention, restricting the self-reliance of the device, and 
$\mathrm{KBr}$ produced as by-product led to recurrent clogging issues. At this stage, we considered how such a simple transformation could lead to almost inextricable issues due to conflictual solubility behavior. We reasoned that $\mathrm{KBr}$ resulting from the alkylation of sesamol $\mathbf{6}$ with allyl bromide is only soluble in aqueous solvents while allylated sesamol 7 readily crystallized in water. Regarding the base, most inorganic bases are insoluble in organic solvents while organic bases such as DBU are weakly soluble in aqueous solvents. After considerable experimentations we profoundly modified the initial procedure developed in batch by replacing $\mathrm{K}_{2} \mathrm{CO}_{3}$ with $\mathrm{KOH}$, allyl bromide with allyl iodide and acetone with a mixture of $\mathrm{MeOH} / \mathrm{H}_{2} \mathrm{O}(95 / 5, \mathrm{v} / \mathrm{v})$. In these conditions all reagents and products were soluble at concentrations of $c a$. $0.5 \mathrm{M}$ and one of the keys of these findings is the switch of allyl bromide for allyl iodide since KI produced as by-product is much more soluble than $\mathrm{KBr}$. While at this stage we fixed all solubility issues we had no certainty and even no experimental evidence for the success of the alkylation in such unusual conditions. Indeed, using very reactive allyl iodide in aqueous methanol with potassium hydroxide as a base seemed counterintuitive due to the number of side-products which could be anticipated (i.e., allyl alcohol, allyl methyl ether, diallyl ether...) and, as we might fear, preliminary test conducted in batch failed to give the expected allylated product 7. We, however, expected a different reaction outcome under flow conditions due to specific mixing effects.

We then turned our attention to the maximization of the reaction yield with our automated system by varying the ratio of allyl iodide to sesamol $\mathbf{6}$, the residence time and the temperature. In this event, a two-stream flow setup including an on-line HPLC was elaborated as depicted in Scheme 2. In the first way, a mixture of sesamol $6(0.4 \mathrm{M})$ and $\mathrm{KOH}(0.6 \mathrm{M})$ in $\mathrm{MeOH} / \mathrm{H}_{2} \mathrm{O}(95 / 5)$ was continuously pumped and meet, in a T-shaped mixer, a second stream consisting of allyl iodide $(0.8 \mathrm{M})$ in $\mathrm{MeOH} / \mathrm{H}_{2} \mathrm{O}(95 / 5)$. The reaction occurred in a stainless steel reactor coil $(2 \mathrm{~mL})$ placed in an oven. At the outlet of the reactor, a back pressure regulator (BPR) maintained the pressure at $c a .15$ bar. An automatic 2-way 6-port switch valve injected a small amount of the reaction stream into the HPLC line. The calculated yield was sent to the algorithm which proposed a new set of conditions and modified the experimental parameters accordingly. We ruled out the use of a benchtop NMR spectrometer as in-line analytical tool due to the impossibility to discriminate ${ }^{1} \mathrm{H}$ resonances of sesamol 6 from the reaction product 7 . 


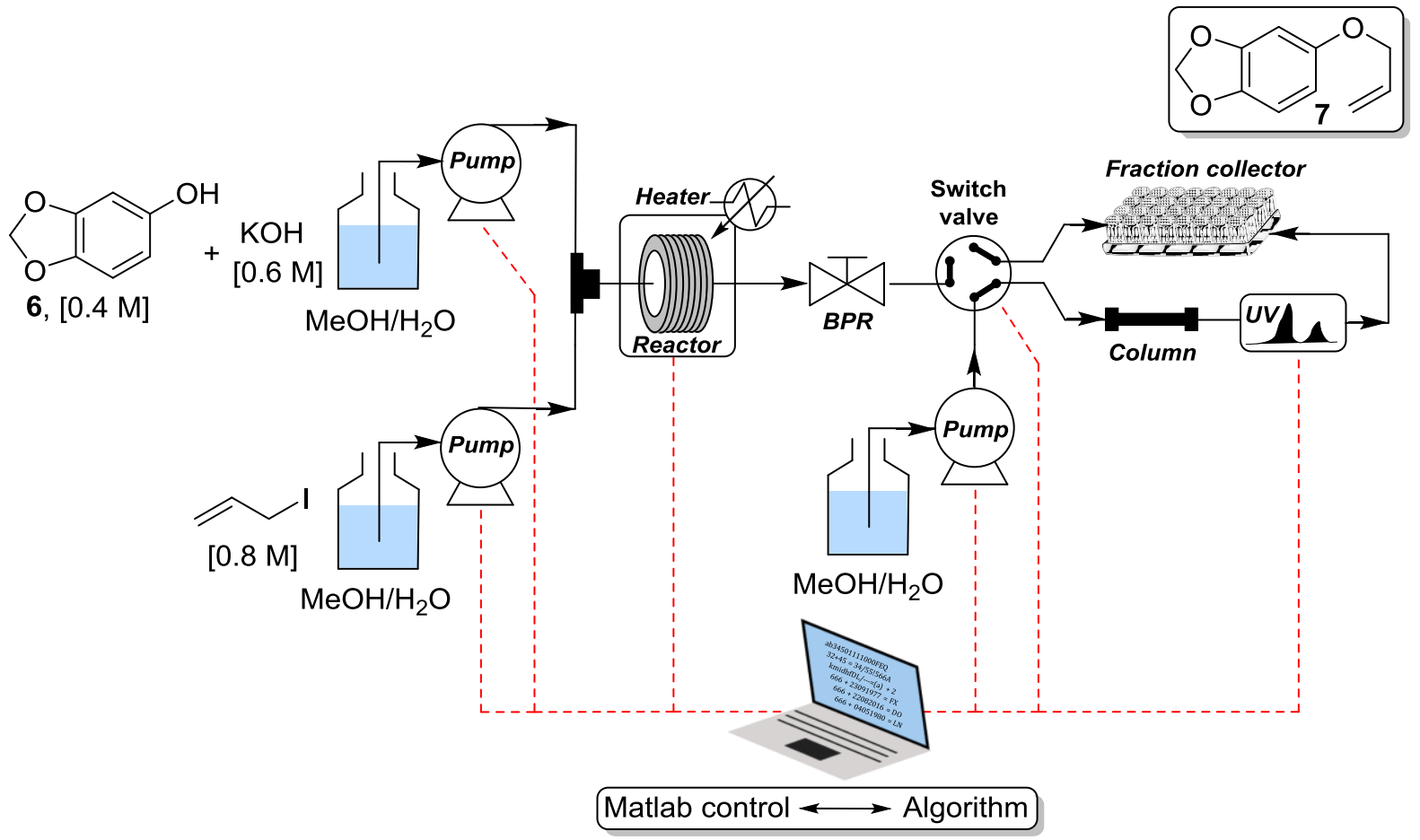

SCHEME 2. Schematic representation of the self-optimizing device used for the optimization of 7 . The red dashed lines indicate the units controlled by the algorithm.

The optimization of this step considered three variables (i.e., temperature, residence time and stoichiometry) and was launched from the initial point $X_{0}$ at $25{ }^{\circ} \mathrm{C}, 10 \mathrm{~min}$ of residence time and 1 equivalent of allyl iodide. The $d$ values of $25^{\circ} \mathrm{C}, 10$ minutes of residence time and 0.5 equivalents of allyl iodide selected for this optimization allowed to construct the initial simplex formed by 4 points. The search space was defined by the following boundaries: $25-$ $100{ }^{\circ} \mathrm{C}, 5-90 \mathrm{~min}$ and 1-3 equiv. for the temperature, residence time and stoichiometry, respectively. The reaction yields automatically calculated by HPLC analysis were in the range of 25 to $54 \%$ for the four initial experiments. The optimization further progressed in a fully autonomous manner and a maximum yield of $80 \%$ was reached at $75{ }^{\circ} \mathrm{C}, 33.3$ minutes of residence time and 1.83 equivalents of allyl iodide after only eleven experiments (Figures 2a$\mathrm{b}$ and Figure S2 in SI). The optimization method required thirteen experiments to terminate the search after determining that the function values of the last simplex were very similar; the standard deviation of the yield for the last simplex was $0.82 \%$ (see Table S1 in SI for details on each experiment). This very satisfactory optimization campaign attests to the powerfulness of our self-optimizing flow reactor, since it successfully optimized the allylation of sesamol 6 under reaction conditions that could be (erroneously) considered as not suitable. It also attests to the impressive orthogonal behavior of reacting partners in batch vs. flow conditions. 

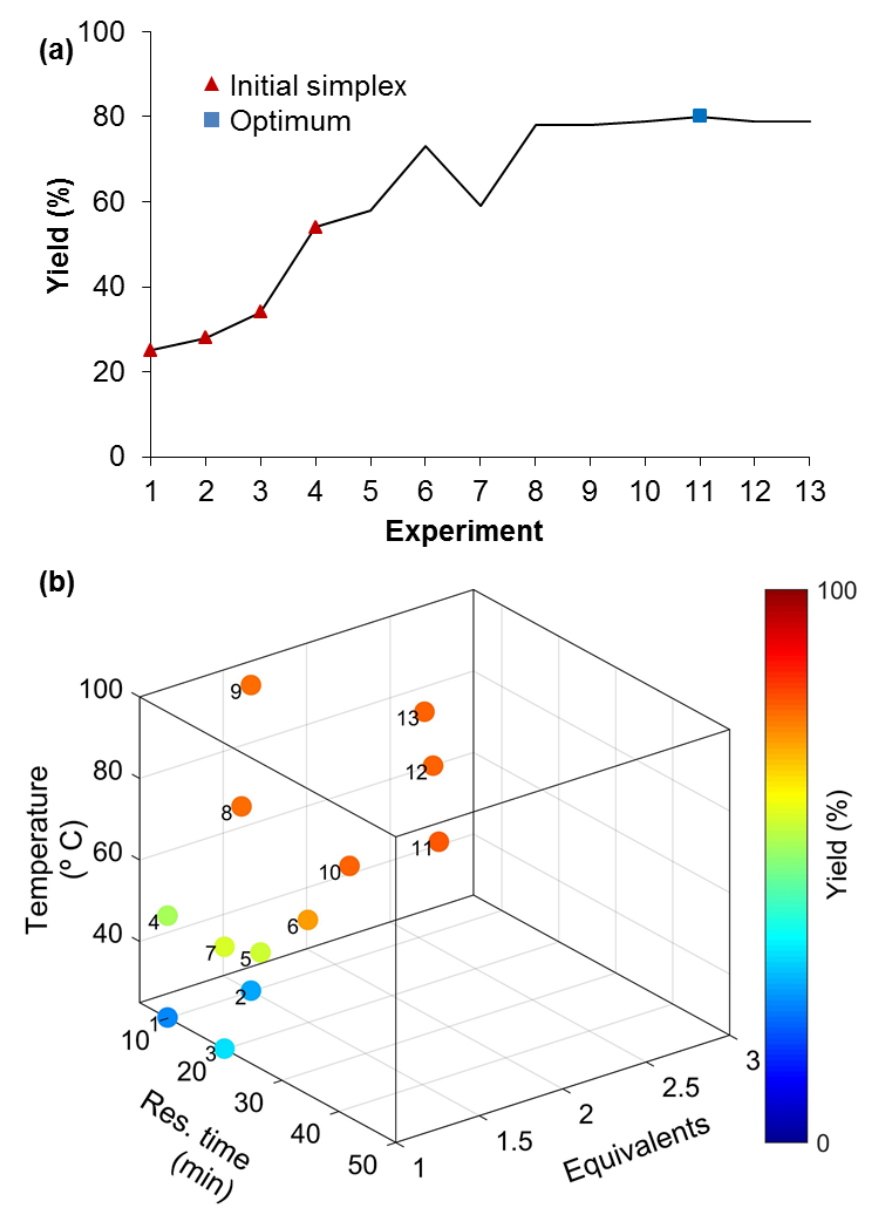

FiguRE 2. (a) Maximization of the yield of 7. (b) Representation of the three-dimensional experimental conditions for the maximization of the yield of 7 .

The second step consisted in a [3,3]-Claisen rearrangement of allyl sesamol $\mathbf{6}$. Traditionally, sigmatropic rearrangements of allyl phenols are carried out under photochemical, ${ }^{64-65}$ catalyst ${ }^{66}$ or thermal activation. ${ }^{67}$ For the latter, high boiling point solvents such as toluene, xylenes and diphenyl ether are required, but we reasoned that the possibility to pressurize the line with an automated BPR could be an appealing opportunity to reach high temperatures with a low boiling point and more sustainable solvent. With this objective in mind we screened a selection of solvents featuring both requirements and having a high solvency power for 7. From this work, we identified acetone as an interesting solvent, though, we were well aware that it was not a common media for [3,3]-sigmatropic rearrangement and might give disappointing results. As the thermally induced [3,3]-Claisen rearrangement did not require any additive and could be executed at elevated concentration ( $2 \mathrm{M})$, we elaborated a self-optimizing flow system holding an in-line benchtop NMR spectrometer (Scheme 3). The reaction setup featured an automatic sample handler introducing $1.5 \mathrm{~mL}$ of compound 7 
at $[1.5 \mathrm{M}]$ in the stream. The $[3,3]$-sigmatropic rearrangement occurred in a stainless steel reactor $(5 \mathrm{~mL})$ heated at temperature up to $250{ }^{\circ} \mathrm{C}$ and pressurized at 70 bar with an electronic BPR to avoid the vaporization of acetone. The NMR flow cell was filled in-line and the crude mixture was analyzed on the fly through quantitative NMR experiments. The resulting data were automatically processed and specific signals arising from starting and final products, respectively, were integrated and the subsequent conversion rate was submitted to the optimization algorithm.

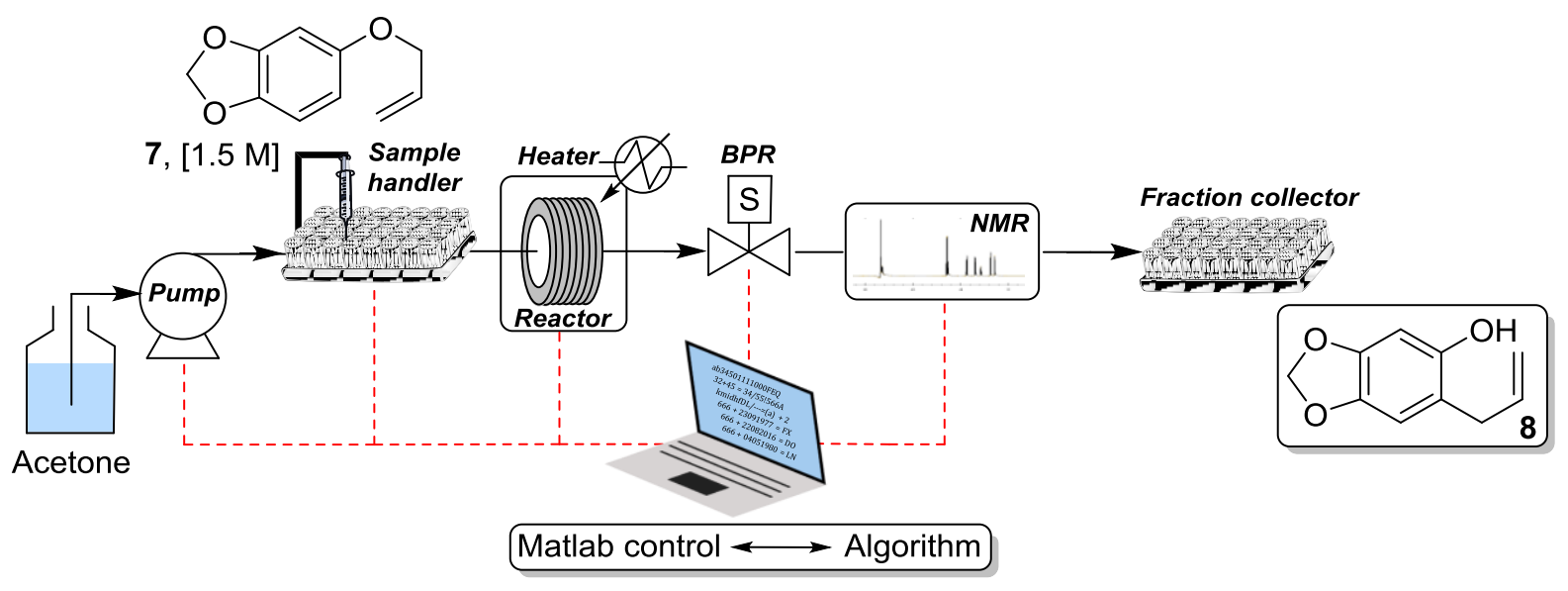

SCHEME 3. Schematic representation of the self-optimizing device used for the optimization of $\mathbf{8}$. The red dashed lines indicate the units controlled by the algorithm.

The flow rate and NMR acquisition conditions were optimized to ensure accurate and precise quantitative NMR data. Although the practical benefit of using a non-deuterated solvent is obvious, the resulting ${ }^{1} \mathrm{H}$ NMR spectra were severely hampered by broad and intense solvent peaks. To circumvent this critical limit, an efficient and robust solvent suppression method - adapted to flowing conditions - was used to yield exploitable NMR data (Figure S3 in SI). In addition, the flow rate was optimized to take into account: $(i)$ the continuous replenishment of the excited spins by unexcited ones; (ii) the minimum time that spins should spend within the pre-polarization volume to reach full thermal polarization and (iii) the loss of excited spins leaving out the sensitive volume before the end of the acquisition. The last two features (ii) and (iii) limit the flow regime to a maximum value of 2 $3 \mathrm{~mL} / \mathrm{min}$ to ensure an optimum sensitivity while $(i)$ leads to an improved sensitivity per unit of time in flow compared to static conditions, since the reduction of the effective relaxation times allows to shorten the recovery delay between successive NMR scans. The repetition delay was fixed above five times the longest $T_{1}$ involved at the slowest flow rate to vouch 
similar quantitative conditions when the residence time is a variable of the optimization procedure. NMR experiments with solvent suppression were performed in 1 min $(6$ scans separated by $10 \mathrm{~s}$ ), delivering spectra with a sufficient sensitivity and resolution (Figure S3 in SI). Further details concerning the NMR experiment and the automatic processing are available in SI.

First, we aimed to maximize the yield in a 2-dimension space where the residence time and the temperature were set as variables in the range of $2.5-50 \mathrm{~min}$ and $50-250{ }^{\circ} \mathrm{C}$, respectively. The initial point $X_{0}$ was randomly fixed at $100{ }^{\circ} \mathrm{C}$ and 3.3 minutes of residence time with $d$ values of $50{ }^{\circ} \mathrm{C}$ and 50 seconds (corresponding to $25 \%$ of the initial residence time). Unfortunately, the three points of the first simplex corresponded to experiments failing to give the expected rearranged compound 8. This situation was foreseen by the optimization algorithm which automatically proposed a random restart with a new initial point $X_{0}$ but keeping the initial $d$ values. We conditioned the random restart proposed by the machine to a manual validation by the chemist in charge of the optimization, but it could be programmatically automated as well if required. The new $X_{0}$ point, that we accepted, randomly fixed the temperature at $172{ }^{\circ} \mathrm{C}$ and the residence time at 22.1 minutes and it corresponded to a reaction yield of $c a .8 \%$. When the temperature reached $222{ }^{\circ} \mathrm{C}(172+d)$ with a residence time of 22.1 minutes, for the third point of the simplex, the reaction yield of 8 spectacularly increased to $99 \%$ (Figures 3a-b). A single reflection of the simplex extended the residence time to 27.6 minutes and provided a reaction yield of $100 \%$ (Figure 3, see also Table S2 in SI for details on each experiment). As the objective function could not be further improved the search stopped after only seven experiments including the failed initial simplex. While the optimization provided a perfect yield in a very limited number of experiments, it was not fully satisfactory since the optimum corresponded to a residence time of 27.6 minutes and a modest productivity of $854 \mathrm{mg} / \mathrm{h}$ for $\mathbf{8}$. Since we suspected that the reaction was mainly governed by the reaction temperature, we reasoned that we might keep high the reaction yield under faster flow rate conditions and thereby, significantly increase the throughput for $\mathbf{8}$. 

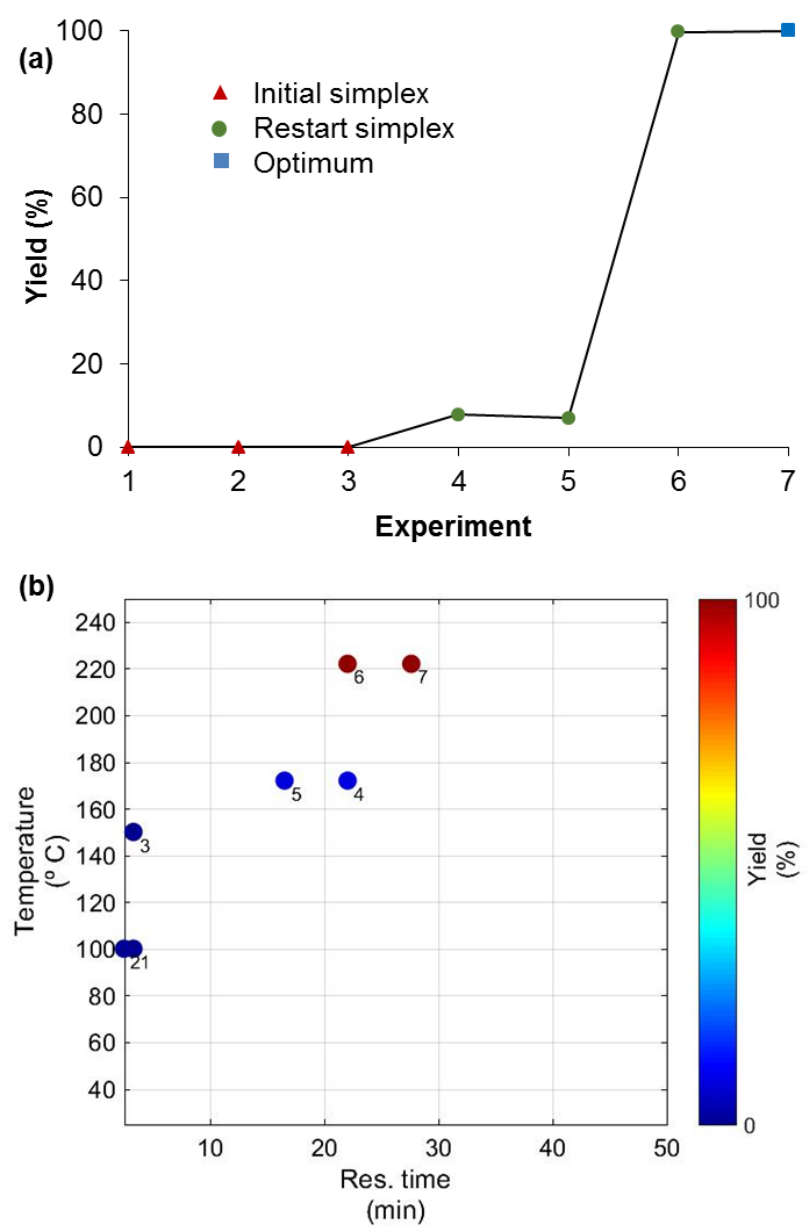

FiguRE 3. (a) Maximization of the yield of 8. (b) Representation of the two-dimensional experimental conditions for the maximization of the yield for $\mathbf{8}$.

In this event, we modified the objective function to maximize the productivity of $\mathbf{8}$ and a new optimization search was launched in the region area of $50-250{ }^{\circ} \mathrm{C}$ and $2.5-50 \mathrm{~min}$ for the temperature and residence time, respectively. The initial point $X_{0}$ was fixed at $150{ }^{\circ} \mathrm{C}$ and 15 minutes of residence time with $d$ values of $50{ }^{\circ} \mathrm{C}$ and 225 seconds (corresponding to $25 \%$ of the initial residence time). The optimization algorithm reached the upper bound of the temperature $\left(250{ }^{\circ} \mathrm{C}\right)$ after two successful reflections. Since no more than $n$ vertices of the simplex could be projected on a boundary of the search domain without harming the convexity of the simplex, ${ }^{48}$ the algorithm automatically reduced the dimension of the search (from 2 to 1 ) after attempting to project an $n+1^{\text {th }}\left(3^{r d}\right)$ vertex of the simplex on the boundary. Hence, the golden section method automatically started to explore such boundary by fixing the temperature to $250{ }^{\circ} \mathrm{C}$ and setting the residence time as a free variable. After 10 experiments, the golden section method terminated the 1 -dimension search by finding that the experiments were close enough to be considered as experimentally equal; a standard deviation 
of 0.16 min was recorded between experiments $15^{\text {th }}$ and $16^{\text {th }}$ (Figures $4 a-b$ ). Since the optimum yet found (experiment $16^{\text {th }}$ ) was constrained to a boundary, the algorithm proposed a dimension recovery to explore its vicinity. The dimension recovery lead to an optimum at the $19^{\text {th }}$ experiment, with $250{ }^{\circ} \mathrm{C}$ and 2.5 minutes of residence time. After such exploration, the algorithm attempted to repeat one of the already performed experiments (i.e. the $19^{\text {th }}$ experiment) and hence it proposed a random re-start, which we rejected. Through this optimization, the productivity of $\mathbf{8}$ was spectacularly increased from $758.3 \mathrm{mg} / \mathrm{h}$ for the initial simplex to a maximum of $7.5 \mathrm{~g} / \mathrm{h}$ after 19 experiments in only one working day (Figure 4 and Table S3 in SI). Two important features should be credited to this work. First, the mechanism of the golden section search implemented in our algorithm greatly facilitated the search and allowed to maximize the throughput with a limited number of experiments. Second, under the optimized conditions, the [3,3]-Claisen rearrangement requires a residence time of only 150 seconds at $250{ }^{\circ} \mathrm{C}$ and 70 bar of pressure. Under such demanding conditions acetone reaches its supercritical state and this work documents the still under developed area of chemical reactions carried out in organic solvent under supercritical conditions. ${ }^{52,68-73}$ This intensified continuous-flow process was rapidly and safely optimized with our autonomous flow device thanks to the use of a unique system associating $(i)$ an automated BPR which prevents acetone to vaporize upon heating over its boiling point with (ii) a benchtop NMR for a fast in-line analysis and (iii) an algorithm allowing a feedback optimization in flow. 

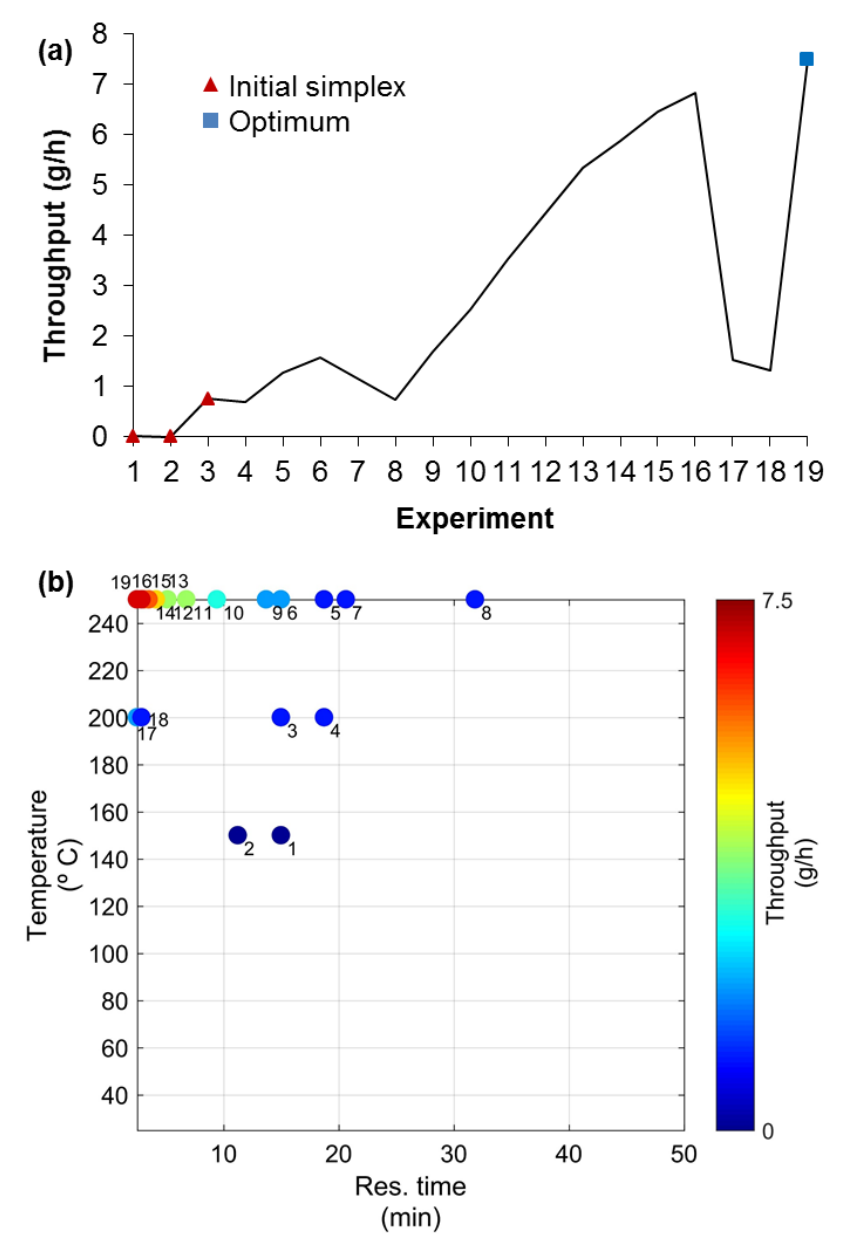

FIGURE 4. (a) Maximization of the productivity of 8. (b) Representation of the twodimensional experimental conditions for the maximization of the throughput for $\mathbf{8}$.

The next step consisted in the isomerization of allyl sesamol 8 to desmethoxycarpacine 9. With a superficial look at this transformation one could erroneously consider it as trivial. Actually, the isomerization of allyl sesamol $\mathbf{8}$ can lead to $E$ and $Z$ isomers of desmethoxycarpacine 9 which are, in turn, highly sensitive to traces of oxygen, leading to benzopyrans. $^{51}$ The stability of $(E)-\mathbf{9}$, which is the desired isomer, was evaluated in preliminary studies. In our hands, we observed that neat $(E)-9$ was stable at $-20{ }^{\circ} \mathrm{C}$ under argon for months while at $25{ }^{\circ} \mathrm{C}$ it degraded after several days. The behavior is radically different in solution $\left(\mathrm{CH}_{2} \mathrm{Cl}_{2}\right)$, as $\mathrm{ca}$. $50 \%$ of $(E)-9$ was converted to benzopyrans after 5 hours at $25{ }^{\circ} \mathrm{C}$. Protecting the solution from light slightly slowed down the conversion ( $\mathrm{ca} .35 \%$ ); while storing the solution at $-20{ }^{\circ} \mathrm{C}$ for 5 hours did not completely suppress the formation benzopyrans (ca. 5\%). This picture is the perfect example where a rapid on-line analysis is strongly required to prevent time-consuming handling that would modify the content of the crude mixture. The isomerization of allyl sesamol $\mathbf{8}$ to desmethoxycarpacine $\mathbf{9}$ has been 
previously carried out with a polymer-supported iridium catalyst with both an excellent yield (97\%) and a high $E / Z$ ratio of $11 / 1$ at $25{ }^{\circ} \mathrm{C}$ for 24 hours. ${ }^{50}$ A base-mediated approach was also reported using $t$-BuOK in DMSO at $100{ }^{\circ} \mathrm{C}$ for 1.5 hours. Under these experimental conditions, desmethoxycarpacine 9 was obtained in good yield (75\%) and a modest $E / Z$ ratio of $7 / 3$. While the base-mediated approach was objectively less efficient than the Ir-catalyzed process, the long reaction time ( 24 hours) required for the latter and the need to pre-activate the Ir catalyst under $\mathrm{H}_{2}$ before use, seriously complicated a transfer to a flow regime. Moreover, we reasoned than both the yield and the $E / Z$ ratio could be optimized with the autonomous flow device.

We initially explored the possibility of executing the isomerization with either $\mathrm{KOH}$ or $t$ $\mathrm{BuOK}$ as the base in sustainable solvents such as EtOH and Me-THF. While promising results were obtained from these preliminary experiments conducted in batch, we experienced recurrent and unpredictable clogging issues in flow, even at concentration as low as $0.01 \mathrm{M}$. After further solubility tests, DMSO was found to be the only solvent giving a clear homogeneous solution of allyl sesamol $\mathbf{8}, t$-BuOK as the base and anisole as the internal standard.

The optimization of the isomerization was carried out with a two-stream flow setup integrating an on-line HPLC unit (Scheme 4). In the first line, an automatic sample handler injects $750 \mu \mathrm{L}$ of a mixture of allyl sesamol $8(0.1 \mathrm{M})$ and anisole $(0.7 \mathrm{M})$ in dry DMSO. The content of the line was telescoped with $t$-BuOK $(0.1 \mathrm{M})$ in a T-shaped piece and the resulting mixture was heated in a stainless steel reactor coil $(5 \mathrm{~mL})$. A 2-way 6-port switch valve was assembled at the outlet of the reactor to inject a fraction of the crude mixture within the HPLC unit which determines the reaction yield for the $(E)$-isomer. The main line was pressurized at 20 bar with an electronic back pressure regulator. 


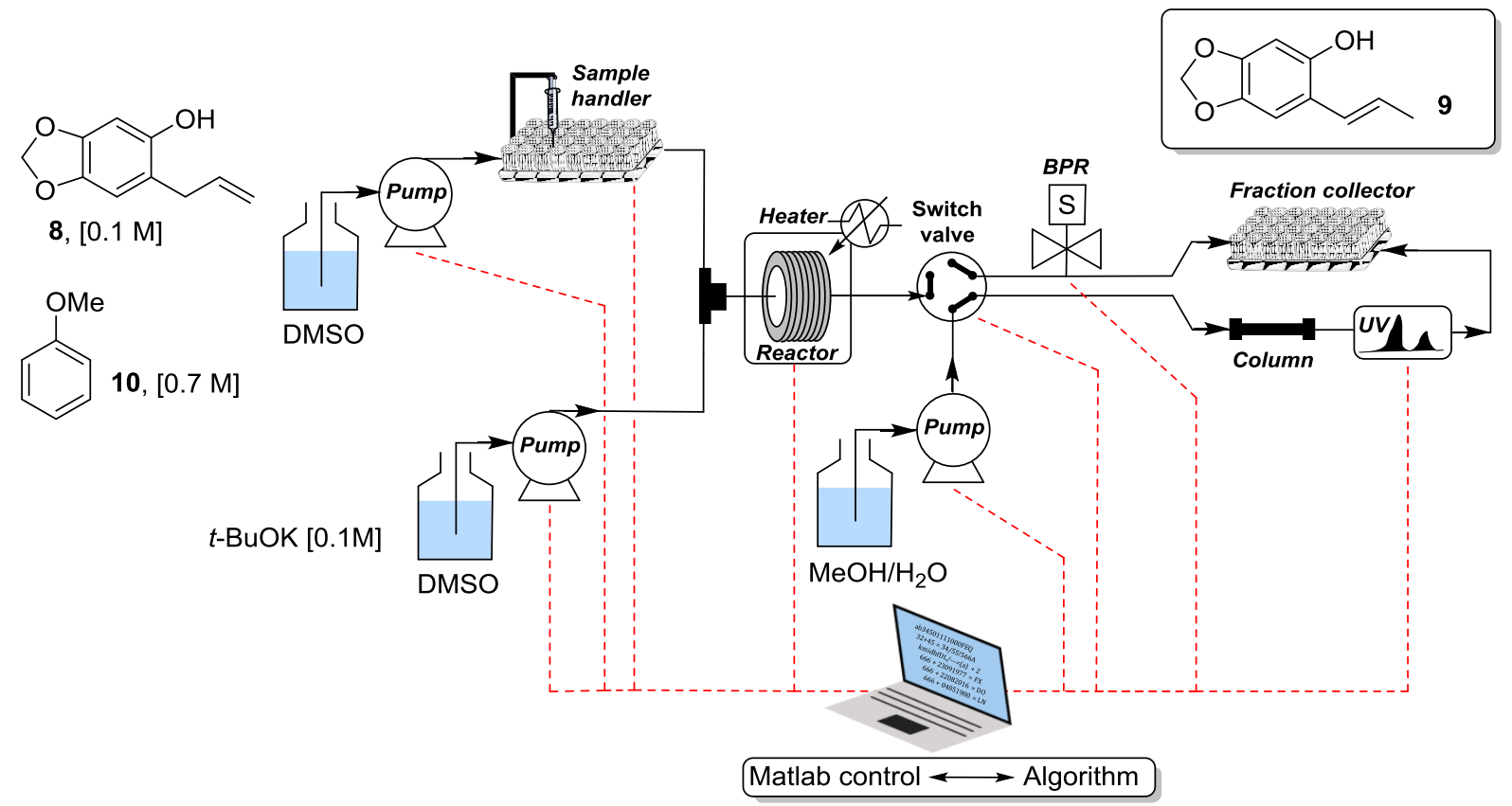

SCHEME 4. Schematic representation of the self-optimizing device used for the optimization of desmethoxycarpacine $\mathbf{9}$. The red dashed lines indicate the units controlled by the algorithm.

The reaction yield was optimized with the temperature, residence time and base loading as variables. The optimization started from the initial point $X_{0}$ at $150{ }^{\circ} \mathrm{C}, 1 \mathrm{~min}$ of residence time and 1 equiv. of $t$-BuOK, with $d$ values of $50{ }^{\circ} \mathrm{C}, 5 \mathrm{~min}$ and 0.25 equiv., respectively (Figure 5). In addition to the linear constraints imposed by the upper/lower bounds of the input variables, we restricted the search space with $n-1$ dimensional surfaces described by the linear combination of the input variables (see details in SI). Here in particular, the 3D search space was constrained by planes (non-parallel to any of the coordinate axes) which automatically discarded experiments that were not experimentally interesting (i.e. short experiments at low temperature, which precluded decent conversion; and long experiments at high temperature, which favored product degradation). The planes constraining the 3D search space act as regular boundaries and hence all the features of the algorithm are active over the planes (e.g. the optimization method could project a simplex on one of the planes and perform a $2 \mathrm{D}$ simplex search over it).

In the initial simplex, three experiments carried out at $150{ }^{\circ} \mathrm{C}$ failed to produce the desired desmethoxycarpacine 9 while the experiments conducted at $200{ }^{\circ} \mathrm{C}$ produced $15 \%$ of 9 . This result suggested that a high temperature was required $\left(\mathrm{ca} .200^{\circ} \mathrm{C}\right)$ to induce the isomerization with short residence times. After four successful reflections, the optimization algorithm reached the lower bound of the base loading and it automatically reduced the dimension of the search (from 3 to 2 ) by fixing the base loading to 1 equivalent. As it was unable to find a 
better optimum in a 2-D search, the algorithm proposed a random restart after 12 experiments. We accepted the random restart proposed by the algorithm with a new $X_{0}$ point at $191{ }^{\circ} \mathrm{C}, 3.3$ min of residence time and 1.23 equivalent of $t$-BuOK. The yield spectacularly increased, up to $80 \%$, with this new simplex, suggesting that the loading of $t$-BuOK strongly affect the reaction outcome. The algorithm further progressed, reaching 91\% yield in experiment 23 . Contrary to the previous steps, the algorithm was unable to stop by reaching similar function and/or simplex values, which evidenced certain roughness in the objective function. The algorithm stopped by reaching the predefined (by the user) maximum number of experiments. The algorithm required user feedback to either continue or stop the optimization. As we considered very satisfactory the optimum found in experiment 23 , we accepted such stopping criterion. Under the optimized conditions found in experiment 23, the reaction yield obtained for the isomerization of allyl sesamol 8 to $(E)$-desmethoxycarpacine 9 reached $91 \%$ while the (Z)-isomer was observed in only trace amounts ( $c a .5 \%$, see Figure S4 in SI). The high E/Z stereoselectivity obtained in our flow regime ( $c$. 95/5) compares favorably to the one obtained in batch ${ }^{51}(E / Z: 70 / 30)$ using the same $t$-BuOK/DMSO couple but in different experimental conditions $\left(100{ }^{\circ} \mathrm{C}\right.$ and $90 \mathrm{~min}$ in batch $v s .190{ }^{\circ} \mathrm{C}$ and $3 \mathrm{~min}$ in flow). Most likely, the high temperature used in flow favors the thermodynamic isomer $(E)-\mathbf{9}$ even under short residence time. 

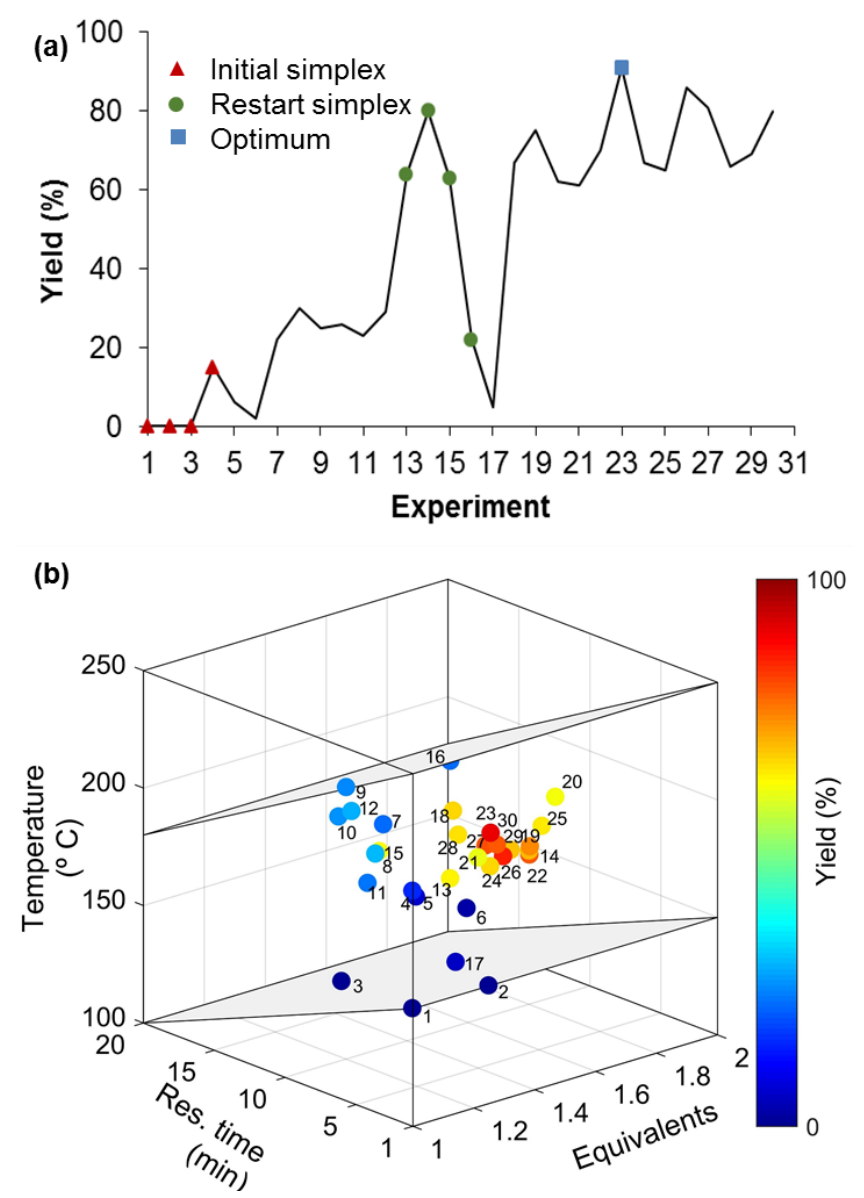

FigURE 5. (a) Maximization of the reaction yield of (E)-9. (b) Representation of the threedimensional experimental conditions for the maximization of the yield for $(E)-\mathbf{9}$. In addition to the upper and lower bounds of the variables, the grey planes represent linear constraints.

The last step, leading to carpanone 1, concerned the oxidative dimerization of desmethoxycarpacin 9. The execution of this step was reported with either stoichiometric ${ }^{49}$ or sub-stoichiometric amount of $\mathrm{PdCl}_{2} ;{ }^{55}$ however, the low solubility of $\mathrm{PdCl}_{2}$ in most organic solvents precluded any possible transfer in a flow reactor. A catalytic $\mathrm{CuCl}_{2} /(-)$-sparteine system was proposed for the oxidative dimerization of styrenyl phenols, but long reactions times $(24 \mathrm{~h})$ and low temperature $\left(-20^{\circ} \mathrm{C}\right)$ are serious limitations for an adaptation in flow. ${ }^{53-}$ 54 Other oxidants such as $\mathrm{PhI}(\mathrm{OAc})_{2},{ }^{74-75}$ 4-methoxy-TEMPO and laccases ${ }^{51}$ were also proposed but all these efficient methods were plagued by high loadings and/or tedious experimental procedure likely unsuitable in flow. Therefore, after having considered several oxidative systems, we reasoned that the use of $\mathrm{Co}^{\mathrm{II}}$ (salen) catalysts ${ }^{51,76}$ addressed most of our concerns for this delicate step. Indeed, several Co ${ }^{\mathrm{II}}$ (salen) catalysts are commercially available and their solubility and activity can be fine-tuned by modification of the salen ligand. Additionally, it might be mentioned that for developing more sustainable processes, the 
synthesis of immobilized Co (salen) catalysts is well known, but this objective is out of the scope of the present study. ${ }^{50,77}$

In preliminary studies, we evaluated the solubility of commercially available $\mathrm{Co}^{\mathrm{II}}$ (salen) catalysts 11 and 12, both in $\mathrm{CH}_{2} \mathrm{Cl}_{2}$ and $\mathrm{C}_{2} \mathrm{H}_{4} \mathrm{Cl}_{2}$ (Figure 6). As anticipated, $\mathrm{Co}$ (salen) 12 bearing $t$-butyl group exhibited a higher solubility than $\mathbf{1 1}$ in both solvents. For our subsequent studies, we privileged the use of $\mathrm{C}_{2} \mathrm{H}_{4} \mathrm{Cl}_{2}$ as the solvent for the optimization campaign as its higher boiling point compared to $\mathrm{CH}_{2} \mathrm{Cl}_{2}$ limited evaporation phenomena that might modify the concentration of initial solutions upon oxygen bubbling.

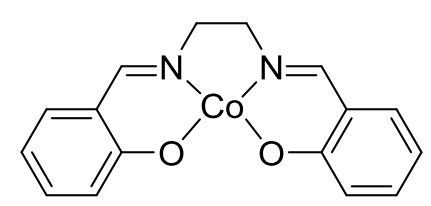

11

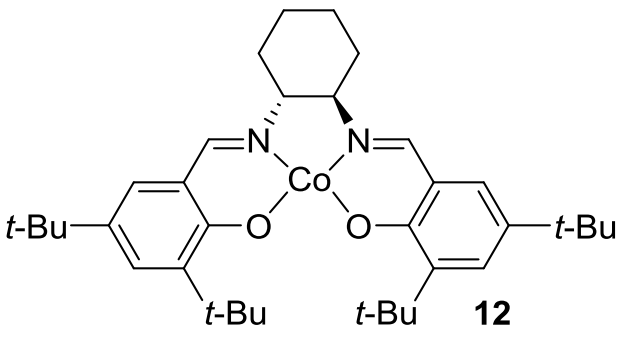

$t$-Bu 12

FigURE 6. Structure of Co ${ }^{\mathrm{II}}$ (salen) catalysts $\mathbf{1 1}$ and $\mathbf{1 2}$.

The autonomous system developed to tackle this challenging step includes two streams and an on-line HPLC unit (Scheme 5). In the first stream, an automatic sample handler injects a sample $(750 \mu \mathrm{L}$ per experience) of styrene $9(0.04 \mathrm{M})$ and $p$-xylene $13(0.4 \mathrm{M})$ as the internal standard in $\mathrm{C}_{2} \mathrm{H}_{4} \mathrm{Cl}_{2}$ while in the second stream $\mathrm{Co}^{\mathrm{II}}$ (salen) $12\left(2.5 \times 10^{-3} \mathrm{M}\right)$ in $\mathrm{C}_{2} \mathrm{H}_{4} \mathrm{Cl}_{2}$, saturated in oxygen, is continuously pumped. Both lines merge in a T-shaped piece and enter in a heated stainless steel reactor coil $(5 \mathrm{~mL})$. The reactor outlet is directly connected to an automated 2-way 6-port switch valve which injects an aliquot of the reaction mixture within the on-line HPLC apparatus for the determination of the reaction yield. 


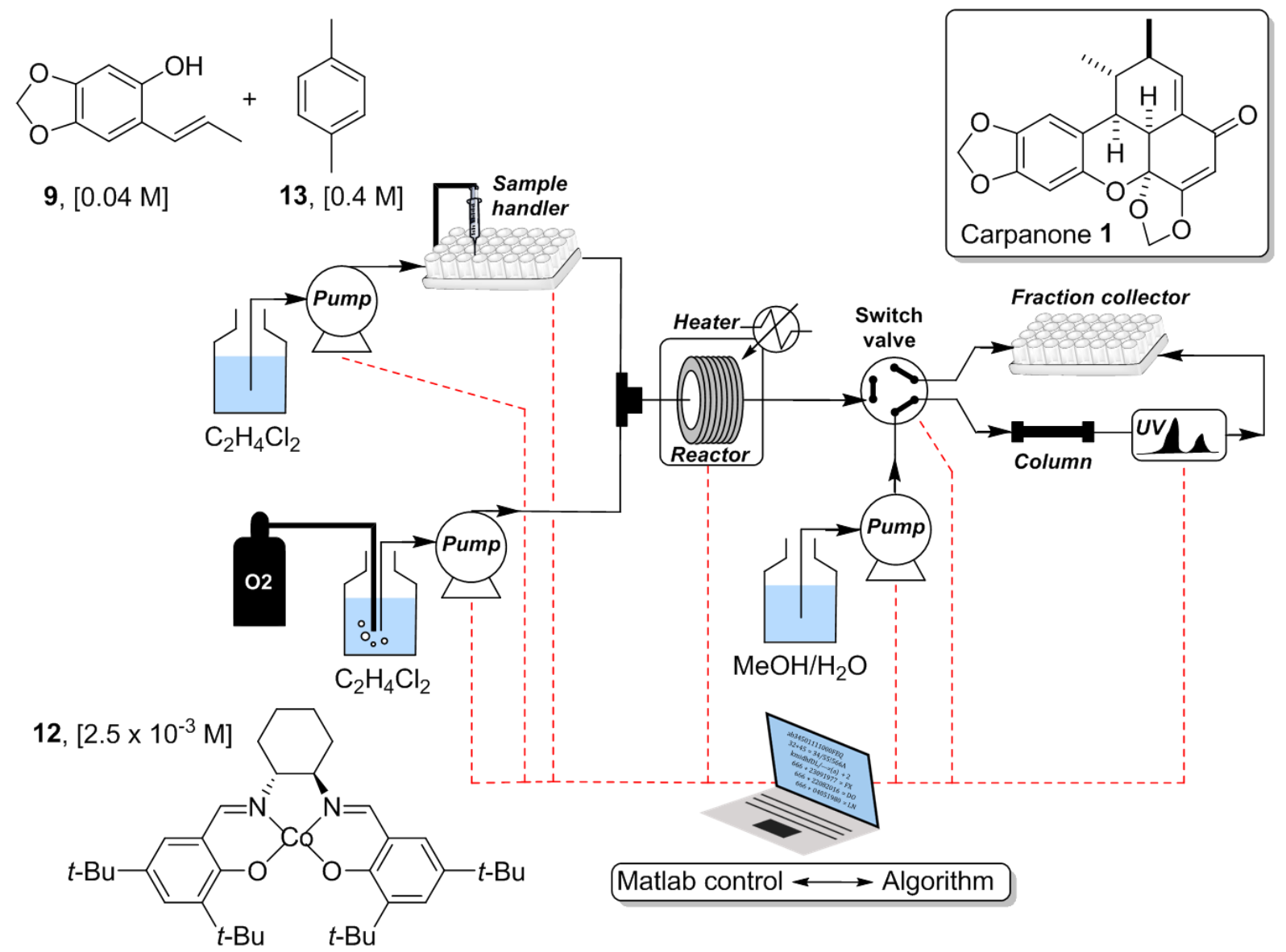

SCHEME 5. Schematic representation of the self-optimizing device used for the optimization of carpanone 1. The red dashed lines indicate the units controlled by the algorithm.

We assigned the maximization of the reaction yield to the autonomous flow device in a 3D space where the temperature, residence time and catalyst loading were selected as continuous variables. The initial point $X_{0}$ was fixed by the operator at $25{ }^{\circ} \mathrm{C}, 1 \mathrm{~min}$ of residence time and $1 \mathrm{~mol} \%$ of catalyst loading, with $d$ values of $10{ }^{\circ} \mathrm{C}, 15 \mathrm{~min}$ and $3 \mathrm{~mol} \%$, respectively. The search space for the three variables was defined as following: $25-60{ }^{\circ} \mathrm{C}, 1-$ $10 \mathrm{~mol} \%$ and 1-60 min for the temperature, catalyst loading and residence time, respectively. The first four experiments, corresponding to the initial 3-D simplex, gave modest reaction yields ranging from 24 to $33 \%$ (Figure 7). After the first simplex, the algorithm increased the value of all variables, evidencing that the effects of the increase of both the catalyst loading and residence time on the yield were prevailing over those resulting from the increase in temperature. Therefore, the optimization method made a sharp increase of catalyst loading and residence time with a gradual (and fluctuating) increase in temperature. The fast growth of the variable values was due to the increase of the simplex size after 3 successful expansions, which allowed to explore the feasible domain from end to end with 7 simplexes 
(13 experiments). Experiments 13-15 were projected on one of the boundaries of the search space by fixing the catalyst loading to the upper bound. Since the algorithm intended to project the $4^{\text {th }}$ point of the simplex (i.e. the $n+1^{\text {th }}$, being $n$ the number of variables) over such boundary, the dimensions of the search were reduced to 2 at a fixed catalyst loading of 10 mol\%. The 2-D simplex formed by experiments 13-15 did a successful reflection to replace the $14^{\text {th }}$ point with the $16^{\text {th }}$, and a stopping criterion was reached by obtaining similar values of yield in the simplex (standard deviation of $2.31 \%$ ). Since the 2-D search failed to increase the reaction yield found in the 3-D search (92\% in experiment 13), the algorithm did not propose a dimension recovery and stopped with an optimum reaching $92 \%$ yield at $40{ }^{\circ} \mathrm{C}, 40$ min of residence time and $10 \mathrm{~mol} \%$ Co catalyst.
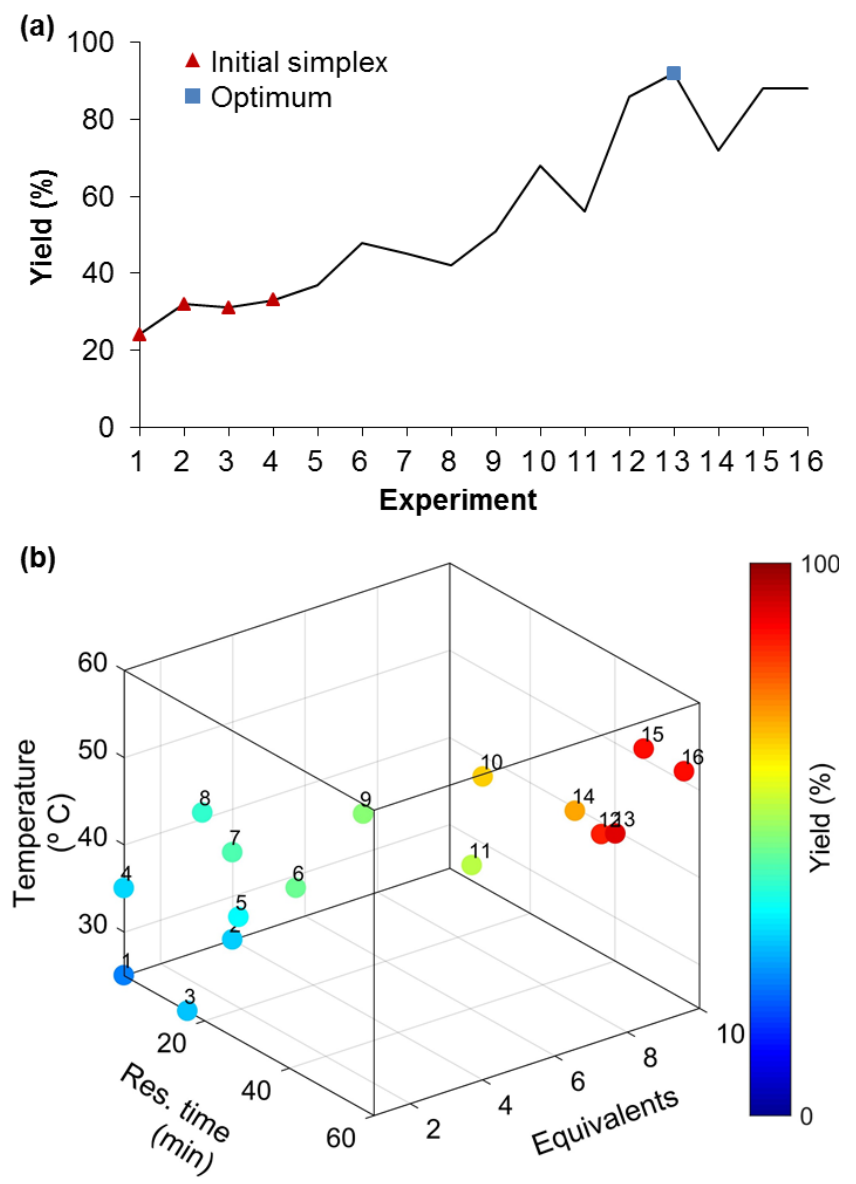

FiguRE 7. (a) Maximization of the yield of 1. (b) Representation of the three-dimensional experimental conditions for the maximization of the yield for carpanone $\mathbf{1}$.

While the initial objective was the maximization of the reaction yield of carpanone $\mathbf{1}$ by integration of the corresponding peak on the HPLC chromatogram at 358 seconds (see Figure S5 in SI), we consistently also observed the formation of trace amount of another product at 
552 seconds retention time. This side product was identified as the carpanone diastereoisomer 14 (Figure 8). ${ }^{51}$

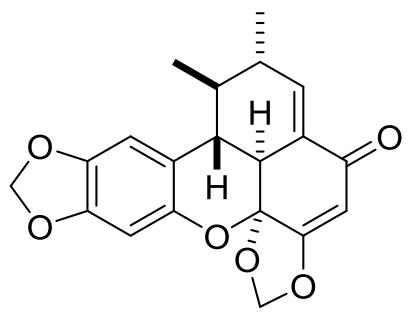

14

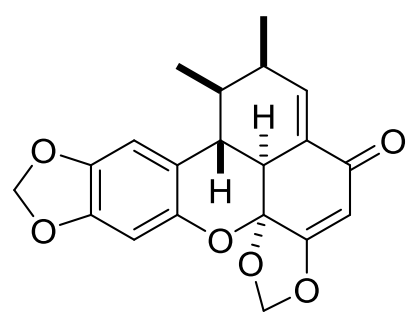

16

FigURE 8. Structure of carpanone diastereoisomers 14 and 16.

The oxidative dimerization of $(E)-9$ has been reported to be completely diastereoselective by most authors whatever the nature of the oxidant. ${ }^{49-50,53,55,76-78}$ By contrast, Beifuss and coworkers pointed out the formation of the carpanone diastereoisomer 14 in a 9/1 : 1/14 ratio which was, in their hands, independent of the nature of the oxidant as $\mathrm{PdCl}_{2}, 4$-methoxyTEMPO and laccase gave the same 1/14 ratio. In our hands, we indeed observed the formation of $\mathbf{1 4}$ as an unseparable diastereoisomer by flash chromatography but in $\mathrm{ca}$. $2 \%$ as measured by the corresponding resonances on the ${ }^{1} \mathrm{H}$ NMR spectrum of carpanone $\mathbf{1}$ (see ${ }^{1} \mathrm{H}$ spectrum of $\mathbf{1}$ in SI). At this stage, the discrepancy between the results from literature and our own observations is still unclear for us and we suspected that the 1/14 ratio could be dependent of either, the purity of $(E)-9$ or the flow regime. In order to get deeper insights, we carried out the oxidative dimerization in batch under the optimized conditions found in flow (i.e., $40{ }^{\circ} \mathrm{C}, 40 \mathrm{~min}$ of reaction time and $10 \mathrm{~mol} \%$ catalyst loading). Under these conditions, we observed the formation of carpanone 1 and its diastereoisomer 14 in a 9/1: 1/14 ratio and $69 \%$ yield, suggesting that the formation of $\mathbf{1 4}$ is highly dependent of the regime of synthesis (flow vs. batch). The formation of caparnone 1, and eventually its diastereoisomer 14, was often rationalized through a mechanistic proposal involving an initial anti- $\beta, \beta$-radical dimerization (Scheme 6). ${ }^{51,76,78}$ However, the perfect anti-diastereoselectivity observed at the methyl groups is difficult to explain through an initial anti- $\beta, \beta$-radical dimerization. Moreover, starting from (Z)-9 would furnish a similar reaction composition as the formation of the radical intermediate $\mathbf{1 5}$ destroys the olefin geometry, but in that case, Beifuss et al. observed the formation of $\mathbf{1}$ and $\mathbf{1 4}$ along with $\mathbf{1 6}$ in a 5/1/4 ratio, respectively. 


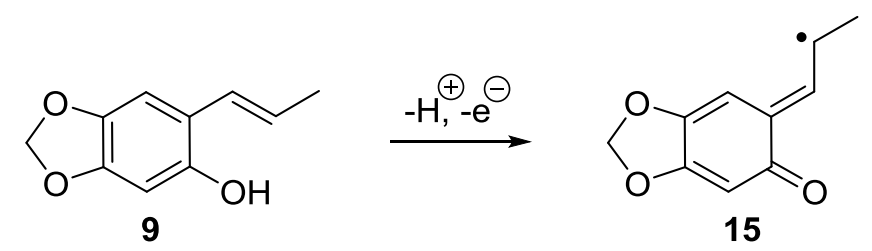

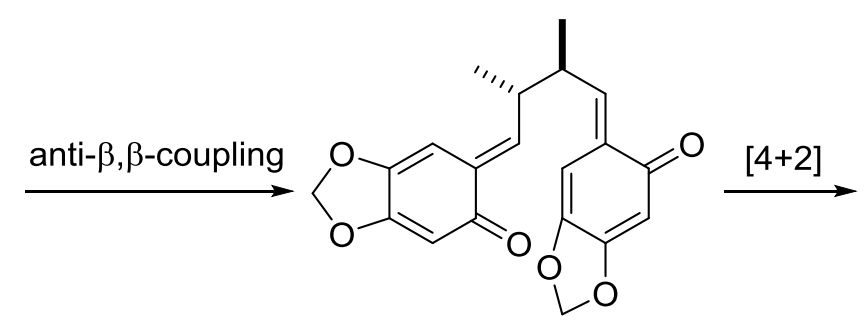<smiles></smiles>

1, endo-product<smiles>CC1C=C2C(=O)C=C3OCOC34CC2(C)[C@H](C)C=C4Oc2cc3c(cc21)OCO3</smiles>

14, exo-product

Scheme 6. Mechanistic proposal involving an initial anti- $\beta, \beta$-radical dimerization

For all these reasons, we believe that a radical-mediated initialization should be ruled out and we instead propose an initial para-quinol coupling followed by an inverse-electron demand endo-[4+2] cycloaddition to furnish carpanone (Scheme 7). Diastereoisomer 14 would be formed by a less favorable exo-[4+2] cycloaddition. 


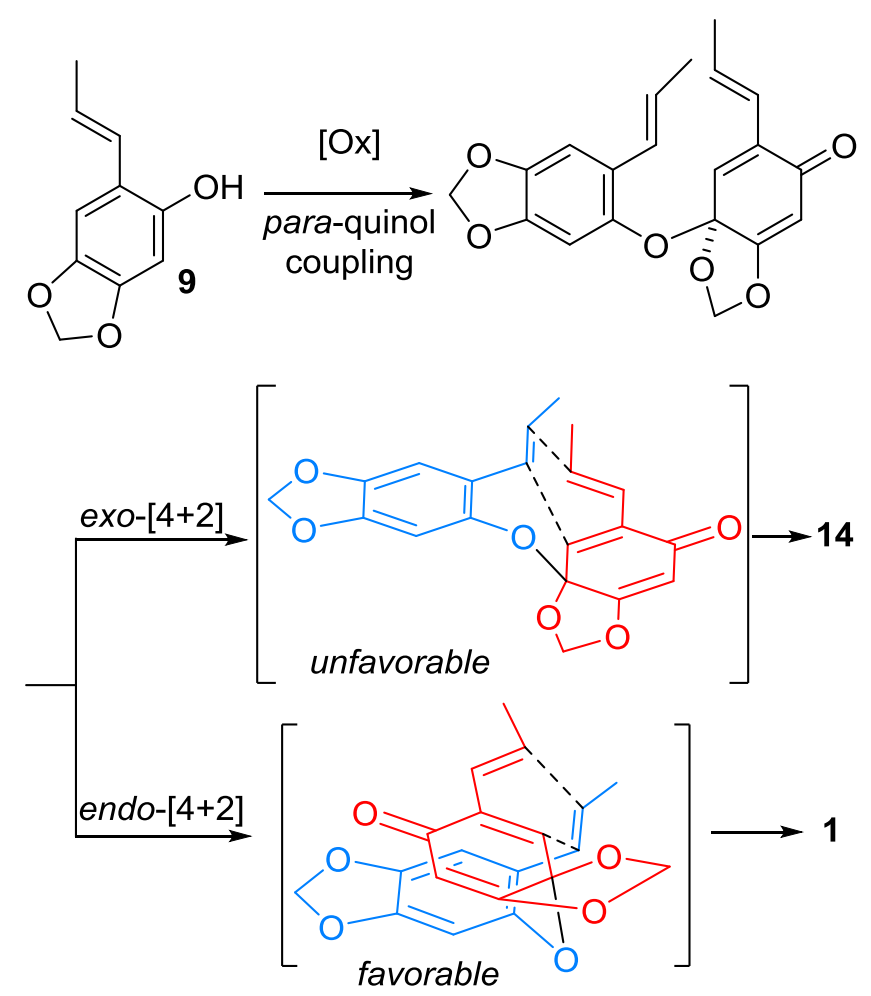

SCHEME 7. Mechanistic rational for the formation of $\mathbf{1}$ and $\mathbf{1 4}$

\section{CONCLUSION}

We demonstrated for the first time that the use of a flexible autonomous self-optimizing flow reactor is a powerful approach to optimize all discrete steps of elaborated architectures, including natural products. Our black-box system assumes no a priori knowledge of the optimal objective function value and is ideally suited for the optimization of reactions with large dimensionality of input continuous variables. For instance, we were able to optimize the synthesis of the natural product carpanone 1 in four steps and $67 \%$ overall yield with a total of 66 experiments. The core of our optimization method lies on the Nelder-Mead and golden section search methods, which are local search methods with low requirement of function evaluations. Our custom-made algorithm features several groundbreaking mechanisms such as $(i)$ dimensionality reduction to explore a boundary, (ii) diversification to search outside the already explored domain, (iii) the possibility to continue the intensification when convergence is reached with an unsatisfactory result, (iv) multiple termination criteria to minimize the number of expensive experiments and $(v)$ the ability to handle linear constraints, either those imposed by the lower and upper bounds of the input variables, or custom constraints expressed as linear relationships between the input variables. 
Our autonomous flow reactor allows, in principle, the optimization of any chemical reactions compatible with a flow regime. Using smart machines to assist chemists in the decision-making process does not mean that people will not be able to think, decide and create anymore. On the contrary, such complex technology allows researcher to focus on intellectually and scientifically more challenging objectives such as reaction discovery while the autonomous system deals with reiterative experiments requiring minimal human intervention. For instance, the mechanism of the oxidative dimerization of $(E)$ desmethoxycapacine 9 to carpanone 1, has been reinvestigated on the basis of the results provided by our machine.

We believe that autonomous machines will massively flood in chemical laboratories in the next years to assist chemists with repetitive, expensive or hazardous experiments. The work described herein is a contribution to the still underdeveloped area of machine-assisted chemistry.

\section{EXPERIMENTAL SECTION}

General information. All commercially available chemicals were used as received unless otherwise noted. ${ }^{1} \mathrm{H}$ and ${ }^{13} \mathrm{C}$ NMR spectra were recorded at 300 or 400 and $75 \mathrm{MHz}$ or 100 $\mathrm{MHz}$, respectively. ${ }^{1} \mathrm{H}$ and ${ }^{13} \mathrm{C}$ NMR spectra were referenced to the internal deuterated solvent $\left(\mathrm{CDCl}_{3}\right)$ at 7.26 and $77.16 \mathrm{ppm}$, respectively. FT-IR spectra were recorded in the ATR mode. Wavelengths of maximum absorbance $\left(v_{\max }\right)$ are quoted in wave numbers $\left(\mathrm{cm}^{-1}\right)$. High resolution mass spectrometry (HRMS) was recorded on a microTOF spectrometer equipped with orthogonal electrospray interface (ESI). Analytical thin-layer chromatography (TLC) was carried out on silica gel $60 \mathrm{~F}_{254}$ plates and visualized with a UV lamp at $254 \mathrm{~nm}$ or stained with a basic potassium permanganate solution. Flash column chromatography was performed using silica gel $60(40-63 \mu \mathrm{m})$. The low-field NMR experiments were performed with a 1T-benchtop spectrometer (Spinsolve, Magritek) operating at a frequency of 43.62 $\mathrm{MHz}$ and equipped with a flow-cell (inner diameter of $4 \mathrm{~mm}$ ). This equipment also includes a gradient coil along the $\mathrm{B}_{0}$-axis (i.e. along the transverse plane of the flow-cell), which can generate a maximum field gradient of $0.16 \mathrm{~T} . \mathrm{m}^{-1}$. This instrumentation enables NMR experiments without deuterated solvents thanks to a built-in external fluorine lock system.

Details of the experimental setup. HPLC pumps (JASCO PU2080) equipped with a RS232 port were employed to flow the solution through the system. A sampler handler (JASCO 
AS 2055) equipped with a RS-232 port was used to inject reagent in the line. The reactor coil was heated with a heating plate (Heidolph, MR Hei-Connect) equipped with a RS-232 port. An electronic back pressure regulator (JASCO BP 2080) equipped with a RS-232 port was used to control the pressure in the line. A 2-way 6-port valve (VICI, Cheminert C2-3006D) equipped with a RS-232 port was used to inject an aliquot of the crude mixture within the online HPLC unit. The HPLC column outlet was connected to a UV detector (JASCO, UV 2075) equipped with a RS-232 port. The flow outlet was connected to a programmable fraction collector (Advantec, CHF 1225C). All units equipped with a RS-232 port were autonomously controlled with MATLAB $^{\circledR}$ through the use of communication protocols provided by the manufacturers. The low-field NMR experiments were performed with a 1Tbenchtop spectrometer (Spinsolve, Magritek) operating at a frequency of $43.62 \mathrm{MHz}$ and equipped with a flow-cell (inner diameter of $4 \mathrm{~mm}$ ). This equipment also includes a gradient coil along the $\mathrm{B}_{0}$-axis (i.e. along the transverse plane of the flow-cell), which can generate a maximum field gradient of $0.16 \mathrm{~T} . \mathrm{m}^{-1}$. This instrumentation enables NMR experiments without deuterated solvents thanks to a built-in external fluorine lock system.

5-Allyloxy-1,3-benzodioxole (7). The experimental setup consisted in two streams as depicted in Scheme 2. The first stream contained a solution of sesamol $6(0.4 \mathrm{M})$ and $\mathrm{KOH}$ $(0.6 \mathrm{M})$ in $\mathrm{MeOH} / \mathrm{H}_{2} \mathrm{O}(95 / 5, \mathrm{v} / \mathrm{v})$ while the second stream contained a solution of alkyl iodide $(0.8 \mathrm{M})$ in $\mathrm{MeOH} / \mathrm{H}_{2} \mathrm{O}(95 / 5, \mathrm{v} / \mathrm{v})$. Each solution was continuously pumped with two independent pumps at the required flow rate, and met in a stainless steel T-shaped piece (internal volume: $0.57 \mu \mathrm{L}$ ). The resulting mixture was introduced in a stainless steel reactor coil $(2 \mathrm{~mL}, 0.75 \mathrm{~mm}$ id) heated at the desired temperature. The reactor outlet was connected to a back pressure regulator (BPR) to maintain the internal pressure at ca. 15 bar. An automatic 2-way 6-port switch valve inject $0.2 \mu \mathrm{L}$ of the crude mixture in the HPLC unit while the remaining stream was collected in a fraction collector. A mixture of $\mathrm{MeOH} / \mathrm{H}_{2} \mathrm{O}$ (70/30, v/v) was used as mobile phase for the HPLC analysis at a flow rate of $1 \mathrm{~mL} / \mathrm{min}$. A UV detector was connected to the outlet of the HPLC column (Agela Promosil C18, 4.6 $\mathrm{mm}^{*} 150 \mathrm{~mm}, 5 \mu \mathrm{m}$ ) to follow the absorbance at a wavelength of $288 \mathrm{~nm}$. Peak integration and yield calculation were under full MATLAB automation. The calculated yield was automatically sent to the algorithm which set new experimental conditions to the units via RS232 ports. A 3-D optimization of the reaction yield was conducted using the temperature, residence time and stoichiometry as the variables. The initial experiment of the simplex was: $25{ }^{\circ} \mathrm{C}, 10 \mathrm{~min}$ and 1 equivalent of allyl iodide. The $d$ values were $25{ }^{\circ} \mathrm{C}, 10 \mathrm{~min}$ and 0.5 
equivalent. The lower and upper boundaries of the research space were the following: 25-100 ${ }^{\circ} \mathrm{C}$, 5-90 min and 1-3 equiv. for the temperature, residence time and stoichiometry, respectively. The details of the 13 experiments carried out with the autonomous flow reactor are given in supporting information (Table S1). An optimum giving 80\% HPLC yield was found in experiment 11 at $75{ }^{\circ} \mathrm{C}, 33.3$ min of residence time and 1.83 equiv. of allyl iodide. An analytical sample of 5-allyloxy-1,3-benzodioxole 7 was obtained by flash chromatography (10\% AcOEt-petroleum ether) as a colourless oil (135 mg, 76\%). IR (ATR) v 2283, 1628, 1483, 1181, 1037, 926, $816 \mathrm{~cm}^{-1} .{ }^{1} \mathrm{H}$ NMR $\left(\mathrm{CDCl}_{3}, 300 \mathrm{MHz}\right): \delta 6.70(\mathrm{~d}, J=8.5 \mathrm{~Hz}, 1 \mathrm{H})$, $6.52(\mathrm{~d}, J=2.5 \mathrm{~Hz}, 1 \mathrm{H}), 6.34(\mathrm{dd}, J=8.5,2.5 \mathrm{~Hz}, 1 \mathrm{H}), 6.03(\mathrm{ddt}, J=17.2,10.6,5.3 \mathrm{~Hz}, 1 \mathrm{H})$, $5.91(\mathrm{~s}, 2 \mathrm{H}), 5.39(\mathrm{dq}, J=17.3,1.6 \mathrm{~Hz}, 1 \mathrm{H}), 5.27(\mathrm{dq}, J=10.5,1.5 \mathrm{~Hz}, 1 \mathrm{H}), 4.46(\mathrm{dt}, J=5.3$, $1.5 \mathrm{~Hz}, 2 \mathrm{H}) .{ }^{13} \mathrm{C} \mathrm{NMR}\left(\mathrm{CDCl}_{3}, 100 \mathrm{MHz}\right.$,): $\delta 154.3,148.4,141.9,133.6,117.7,108.1,106.2$, 101.3, 98.5, 70.0. HRMS (ESI) m/z: $[\mathrm{M}+\mathrm{H}]^{+}$Calcd for $\mathrm{C}_{10} \mathrm{H}_{11} \mathrm{O}_{3}$ 179.0703; Found 179.0703.

6-Allyl-1,3-benzodioxol-5-ol (8). An automatic sample handler injected a solution of 5allyloxy-1,3-benzodioxole $7(1.5 \mathrm{~mL}, 1.5 \mathrm{M}$ in acetone) in a stream of acetone pumped at the required flow rate as depicted in Scheme 3. The [3,3]-Claisen rearrangement occurred in a stainless steel reactor coil $(5 \mathrm{~mL}, 0.75 \mathrm{~mm}$ id) heated at the required temperature. The line was constantly pressurized at 70 bar with an electronic back pressure regulator (BPR) to prevent the vaporization of acetone. The BPR outlet was connected to the NMR flow cell and the crude mixture was analyzed on the fly through quantitative in-line NMR experiments. The ${ }^{1} \mathrm{H}$ NMR spectra with solvent suppression were recorded via a WET-180-NOESY pulse sequence (see supporting information for details). ${ }^{60}$ Results from the NMR experiments were automatically sent to the algorithm which set new experimental conditions to the units via RS232 ports (see supporting information of details). A 2-D optimization of the reaction yield was conducted using the temperature and residence time as the variables. The initial experiment of the simplex was: $100{ }^{\circ} \mathrm{C} 3.33 \mathrm{~min}$ of residence time. The $d$ values were $50{ }^{\circ} \mathrm{C}$ and 50 seconds. The search space was defined by the following boundaries: $50-250{ }^{\circ} \mathrm{C}$ and $25-50$ min for the temperature and residence time, respectively. The details of the 7 experiments carried out with the autonomous flow reactor are given in supporting information (Table S2). An optimum giving 100\% NMR yield was found in experiment 7 at $222.4{ }^{\circ} \mathrm{C}$ and $27.6 \mathrm{~min}$ of residence time. A 2-D optimization of the productivity was conducted using the temperature and residence time as the variables. The initial experiment of the simplex was: $150{ }^{\circ} \mathrm{C} 15 \mathrm{~min}$ of residence time. The $d$ values were $50{ }^{\circ} \mathrm{C}$ and 225 seconds. The search space was defined by the following boundaries: $50-250{ }^{\circ} \mathrm{C}$ and $2.5-50 \mathrm{~min}$ for the temperature and residence time, respectively. The details of the 19 experiments carried out with the autonomous flow reactor 
are given in supporting information (Table S3). An optimum giving $7.5 \mathrm{~g} / \mathrm{h}$ NMR productivity was found in experiment 19 at $250{ }^{\circ} \mathrm{C}$ and $2.5 \mathrm{~min}$ of residence time. An analytical sample of 6-allyl-1,3-benzodioxol-5-ol 8 was obtained by flash chromatography (9\% AcOEt-petroleum ether) as a white solid (132 mg, 74\%). Mp $76{ }^{\circ} \mathrm{C}$ [Lit. $\left.{ }^{51} 75-76{ }^{\circ} \mathrm{C}\right]$. IR (ATR) $v 3232,2909,1639,1455,1155,1029,906,829 \mathrm{~cm}^{-1} .{ }^{1} \mathrm{H} \mathrm{NMR}\left(\mathrm{CDCl}_{3}, 400 \mathrm{MHz}\right): \delta$ $6.58(\mathrm{~s}, 1 \mathrm{H}), 6.43(\mathrm{~s}, 1 \mathrm{H}), 6.02-5.91(\mathrm{~m}, 1 \mathrm{H}), 5.88(\mathrm{~s}, 2 \mathrm{H}), 5.17-5.12(\mathrm{~m}, 2 \mathrm{H}), 4.73(\mathrm{~s}, 1 \mathrm{H})$, $3.31(\mathrm{dt}, J=6.3,1.6 \mathrm{~Hz}, 2 \mathrm{H}) .{ }^{13} \mathrm{C} \mathrm{NMR}\left(\mathrm{CDCl}_{3}, 100 \mathrm{MHz},\right): \delta 148.8,146.9,141.7,136.6$, 117.1, 116.5, 109.7, 101.2, 98.9, 35.2. HRMS (ESI) m/z: $[\mathrm{M}+\mathrm{H}]^{+}$Calcd for $\mathrm{C}_{10} \mathrm{H}_{11} \mathrm{O}_{3}$ 179.0703; Found 179.0702.

(E)-6-(Prop-1-enyl)-1,3-benzodioxol-5-ol (9). The experimental setup consisted in two streams as depicted in Scheme 4. In the first stream, an automatic sample handler injected 750 $\mu \mathrm{L}$ of a solution of 6-allyl-1,3-benzodioxol-5-ol 8 (0.1 M in DMSO) and anisole 10 (0.7 M in DMSO) in a stream of DMSO pumped at the required flow rate. The second stream continuously pumped a solution of $t$ - BuOK $(0.1 \mathrm{M})$ in DMSO at the required flow rate. Both streams merged in a stainless steel T-shaped piece (internal volume: $0.57 \mu \mathrm{L}$ ) and the resulting mixture flowed in a stainless steel reactor coil $(5 \mathrm{~mL}, 0.75 \mathrm{~mm}$ id) heated at the desired temperature. The reactor outlet was connected to a 2-way 6-port switch valve followed by an electronic back pressure regulator (BPR) to maintain the internal pressure at ca. 20 bar. $0.19 \mu \mathrm{mol}$ of the crude mixture was injected in the HPLC unit while the remaining stream was collected in a fraction collector. A mixture of $\mathrm{MeOH} / \mathrm{H}_{2} \mathrm{O}(40 / 60$, v/v) was used as mobile phase for the HPLC analysis at a flow rate of $0.3 \mathrm{~mL} / \mathrm{min}$. A UV detector was connected to the outlet of the HPLC column (Agela Promosil C18, $3 \mathrm{~mm} * 150 \mathrm{~mm}, 5 \mu \mathrm{m}$ ) to follow the absorbance at a wavelength of $260 \mathrm{~nm}$. Peak integration and yield calculation were under full MATLAB automation. The calculated yield was automatically sent to the algorithm which set new experimental conditions to the units via RS-232 ports. A 3-dimensional optimization of the reaction yield was conducted using the temperature, residence time and base loading as the variables. The initial experiment of the simplex was: $150{ }^{\circ} \mathrm{C}, 1 \mathrm{~min}$ and 1 equiv. of $t$-BuOK. The $d$ values were $50{ }^{\circ} \mathrm{C}, 5 \mathrm{~min}$ and 0.25 equiv. The search space was defined by the following boundaries: $25-100{ }^{\circ} \mathrm{C}, 2.5-60 \mathrm{~min}$ and 1-3 equiv. for the temperature, residence time and base equivalents, respectively. The details of the 30 experiments carried out with the autonomous flow reactor are given in supporting information (Table S4). An optimum giving 91\% HPLC yield was found in experiment 23 at $203.6{ }^{\circ} \mathrm{C}, 3.7$ min of residence time and 1.38 equiv. of $t$-BuOK. An analytical sample of (E)-6-(Prop-1enyl)-1,3-benzodioxol-5-ol 9 was obtained by flash chromatography (50\% $\mathrm{CH}_{2} \mathrm{Cl}_{2}$-petroleum 
ether to $70 \% \mathrm{CH}_{2} \mathrm{Cl}_{2}$-petroleum ether) as a pale yellow solid along with (Z)-6-(Prop-1-enyl)1,3-benzodioxol-5-ol as a yellow oil (35 mg, 87\%). (E)-6-(Prop-1-enyl)-1,3-benzodioxol-5-ol 9: m.p. $93{ }^{\circ} \mathrm{C}\left[\right.$ Lit. $\left.^{49} 87-88{ }^{\circ} \mathrm{C}\right]$. IR (ATR) v 3300, 2899, 1631, 1441, 1161, 1030, 927, $832 \mathrm{~cm}^{-}$ 1. ${ }^{1} \mathrm{H}$ NMR (300 MHz, Chloroform-d) $\delta 6.76(\mathrm{~s}, 1 \mathrm{H}), 6.47(\mathrm{dq}, J=15.6,1.8 \mathrm{~Hz}, 1 \mathrm{H}), 6.39$ (s, $1 \mathrm{H}), 6.02(\mathrm{dq}, J=15.7,6.6 \mathrm{~Hz}, 1 \mathrm{H}), 5.89$ (s, 2H), 4.76 (s, 1H), 1.89 (dd, $J=6.6,1.7 \mathrm{~Hz}, 3 \mathrm{H})$. ${ }^{13} \mathrm{C}$ NMR $\left(75 \mathrm{MHz}, \mathrm{CDCl}_{3}\right) \delta 147.4,147.2,142.0,126.8,125.0,117.5,106.1,101.2,98.3$, 18.9. HRMS (ASAP') m/z: [M-H] $]^{-}$Calcd for $\mathrm{C}_{10} \mathrm{H}_{9} \mathrm{O}_{3}$ 177.0552; found 177.0550.

(Z)-6-(Prop-1-enyl)-1,3-benzodioxol-5-ol 9: IR (ATR) v 3474, 2888, 1623, 1440, 1168, 1038, 934, 863 $\mathrm{cm}^{-1} .{ }^{1} \mathrm{H}$ NMR (300 MHz, Chloroform- $d$ ) $\delta 6.56(\mathrm{~s}, 1 \mathrm{H}), 6.48$ (s, 1H), 6.28 (ddt, $J=$ 11.1, 2.2, 1.6 Hz, 1H), 6.03-5.91 (m, 1H), $5.90(\mathrm{~s}, 2 \mathrm{H}), 4.82(\mathrm{~s}, 1 \mathrm{H}), 1.71$ (dd, J = 7.0, $1.8 \mathrm{~Hz}$, 3H). ${ }^{13} \mathrm{C}$ NMR $\left(75 \mathrm{MHz}, \mathrm{CDCl}_{3}\right) \delta 147.7,147.5,141.2,131.0,124.1,115.1,108.5,101.2$, 97.7, 14.7. HRMS (ASAP') m/z: [M-H] ${ }^{-}$Calcd for $\mathrm{C}_{10} \mathrm{H}_{9} \mathrm{O}_{3}$ 177.0552; Found 177.0555.

Carpanone (1). The experimental setup consisted in two streams as depicted in Scheme 5. In the first stream, an automatic sample handler injected $750 \mu \mathrm{L}$ of a solution of (E)-6-(Prop-1enyl)-1,3-benzodioxol-5-ol $9\left(0.04 \mathrm{M}\right.$ in $\left.\mathrm{C}_{2} \mathrm{H}_{4} \mathrm{Cl}_{2}\right)$ and xylene $13\left(0.4 \mathrm{M}\right.$ in $\left.\mathrm{C}_{2} \mathrm{H}_{4} \mathrm{Cl}_{2}\right)$ in a stream of $\mathrm{C}_{2} \mathrm{H}_{4} \mathrm{Cl}_{2}$ pumped at the required flow rate. The second stream continuously pumped a solution of $\mathrm{Co}^{\mathrm{II}}$ (salen) catalyst $12\left(2.5 \times 10^{-3} \mathrm{M}\right)$ in $\mathrm{C}_{2} \mathrm{H}_{4} \mathrm{Cl}_{2}$, saturated with oxygen, at the required flow rate. Both streams merged in a stainless steel T-shaped piece (internal volume: $0.57 \mu \mathrm{L})$ and the resulting mixture flowed in a stainless steel reactor coil $(5 \mathrm{~mL}, 0.75 \mathrm{~mm} \mathrm{id})$ heated at the desired temperature. The reactor outlet was connected to a 2-way 6-port switch valve which introduced $4.80 \mu \mathrm{mol}$ of the crude mixture (related to the internal standard) was injected in the HPLC unit while the remaining stream was collected in a fraction collector. A mixture of $\mathrm{MeOH} / \mathrm{H}_{2} \mathrm{O}(70 / 30$, v/v) was used as mobile phase for the HPLC analysis at a flow rate of $1 \mathrm{~mL} / \mathrm{min}$. A UV detector was connected to the outlet of the HPLC column (Agela Promosil C18, $4.6 \mathrm{~mm} * 150 \mathrm{~mm}, 5 \mu \mathrm{m}$ ) to follow the absorbance at a wavelength of $270 \mathrm{~nm}$. Peak integration and yield calculation were under full MATLAB automation. The calculated yield was automatically sent to the algorithm which set new experimental conditions to the units via RS-232 ports. A 3-dimensional optimization of the reaction yield was conducted using the temperature, residence time and catalyst loading as the variables. The initial experiment of the simplex was: $25{ }^{\circ} \mathrm{C}, 1 \mathrm{~min}$ and $1 \mathrm{~mol} \%$. The $d$ values were $25{ }^{\circ} \mathrm{C}, 15 \mathrm{~min}$ and $3 \mathrm{~mol} \%$. The search space was defined by the following boundaries: $25-60{ }^{\circ} \mathrm{C}, 1-60 \mathrm{~min}$ and $1-10 \mathrm{~mol} \%$ for the temperature, residence time and catalyst loading, respectively. The details of the 16 experiments carried out with the autonomous flow reactor are given in supporting information (Table S5). An optimum giving 92\% HPLC yield was found in 
experiment 13 at $40{ }^{\circ} \mathrm{C}, 40.2 \mathrm{~min}$ of residence time and $10 \mathrm{~mol} \%$ of Co ${ }^{\mathrm{II}}$ (salen) catalyst $\mathbf{1 2}$. An analytical sample of carpanone $\mathbf{1}$ and its diastereoisomer $\mathbf{1 4}$ as an inseparable mixture was obtained by flash chromatography $\left(70 \% \mathrm{CH}_{2} \mathrm{Cl}_{2}\right.$-petroleum ether) in a ratio of 98/2:1/14 as a white solid (26 mg, 82\%). Mp $193{ }^{\circ} \mathrm{C}$ [Lit. ${ }^{51} 189-190{ }^{\circ} \mathrm{C}$ ]. IR (ATR) v 2872, 1674, 1622, 1478, 1158, 1032, 910, $840 \mathrm{~cm}^{-1} .{ }^{1} \mathrm{H}$ NMR (400 MHz, Chloroform- $d$ ) $\delta$ 7.03-7.00 (m, 1H), $6.80(\mathrm{~s}, 1 \mathrm{H}), 6.33(\mathrm{~s}, 1 \mathrm{H}), 5.90(\mathrm{~d}, J=1.4 \mathrm{~Hz}, 1 \mathrm{H}), 5.87(\mathrm{~d}, J=1.4 \mathrm{~Hz}, 1 \mathrm{H}), 5.69$ (s, 1H), 5.66 (s, 1H), $5.64(\mathrm{~s}, 1 \mathrm{H}), 3.27$ (dd, $J=7.4,2.6 \mathrm{~Hz}, 1 \mathrm{H}), 3.19$ (dt, $J=7.5,2.5 \mathrm{~Hz}, 1 \mathrm{H}), 2.52$ (br qd, $J=6.9,2.1 \mathrm{~Hz}, 1 \mathrm{H}), 2.24-2.18(\mathrm{~m}, 1 \mathrm{H}), 1.15(\mathrm{~d}, J=7.2 \mathrm{~Hz}, 3 \mathrm{H}), 0.71(\mathrm{~d}, J=7.6 \mathrm{~Hz}, 3 \mathrm{H}) .{ }^{13} \mathrm{C}$ NMR $\left(100 \mathrm{MHz}, \mathrm{CDCl}_{3}\right) \delta 187.0,168.5,146.8,145.3,143.3,142.7,126.5,115.4,107.3$, 101.4, 100.6, 100.3, 99.4, 98.9, 36.4, 35.6, 35.4, 33.7, 21.6, 21.3. HRMS (ESI) m/z: $[\mathrm{M}+\mathrm{H}]^{+}$ Calcd for $\mathrm{C}_{20} \mathrm{H}_{19} \mathrm{O}_{6}$ 355.1182; Found 355.1180.

Preparation of Carpanone (1) in batch. Co ${ }^{\mathrm{II}}$ (salen) catalyst $12(2.5 \mathrm{mg}, 4.24 \mu \mathrm{mol}, 0.01$ equiv.) was added to a solution of (E)-6-(Prop-1-enyl)-1,3-benzodioxol-5-ol 9 (75.5 mg, 0.42 mmol, 1 equiv.) in $\mathrm{C}_{2} \mathrm{H}_{4} \mathrm{Cl}_{2}(11 \mathrm{~mL})$. The resulting suspension was stirred under $\mathrm{O}_{2}$ at $40{ }^{\circ} \mathrm{C}$ for $40 \mathrm{~min}$. The reaction mixture was cooled at room temperature and was concentrated under reduced pressure. $\mathrm{Et}_{2} \mathrm{O}$ was added and the resulting suspension was filtered under a plug of silica gel to remove the catalyst. The filtrate was concentrated under reduced pressure and the resulting residue was purified by flash chromatography $\left(50 \%\right.$ cyclohexane- $\left.\mathrm{Et}_{2} \mathrm{O}\right)$ to afford a carpanone $\mathbf{1}$ and its diastereoisomer $\mathbf{1 4}$ as an inseparable mixture in a ratio of 90/10 as a white solid (52 mg, 69\%).

\section{ASSOCIATED CONTENT}

The Supporting Information is available free of charge on the ACS Publications website at DOI: 10.1021/acs.joc.Xxxxxx.

NMR spectra of purified products: 7, 8, (E)-9, $(Z)-9$ and $\mathbf{1}$.

\section{AUTHOR INFORMATION}

\section{Corresponding author}

*E-mail: fx.felpin@univ-nantes.fr

\section{ORCID}

François-Xavier Felpin: 0000-0002-8851-246X

Erwan Le Grognec: 0000-0002-3351-7028 
Patrick Giraudeau: 0000-0001-9346-9147

\section{Notes}

The authors declare no competing financial interest.

\section{ACKNOWLEDGEMENTS}

This work was supported by the "Région des Pays de la Loire" in the framework of the "Pari Scientifique Régional SmartCat". D.C.B. gratefully acknowledges the "Région des Pays de la Loire" for a grant. P.G. and F.-X.F. are members of the "Institut Universitaire de France, IUF".

\section{- REFERENCES}

(1) Frisbee, A. R.; Nantz, M. H.; Kramer, G. W.; Fuchs, P. L. Laboratory Automation. 1: Syntheses via Vinyl Sulfones. 14. Robotic Orchestration of Organic Reactions: Yield Optimization via an Automated System with Operator-Specified Reaction Sequences. J. Am. Chem. Soc. 1984, 106.

(2) Ley, S. V.; Ingham, R. J.; O’Brien, M.; Browne, D. L. Camera-Enabled Techniques for Organic Synthesis. Beilstein J. Org. Chem. 2013, 9, 1051-1072.

(3) Skilton, R. A.; Bourne, R. A.; Amara, Z.; Horvath, R.; Jin, J.; Scully, M. J.; Streng, E.; Tang, S. L. Y.; Summers, P. A.; Wang, J.; Pérez, E.; Asfaw, N.; Aydos, G. L. P.; Dupont, J.; Comak, G.; George, M. W.; Poliakoff, M. Remote-Controlled Experiments with Cloud Chemistry. Nat. Chem. 2014, 7, 1-5.

(4) Fitzpatrick, D. E.; Battilocchio, C.; Ley, S. V. Enabling Technologies for the Future of Chemical Synthesis. ACS Cent. Sci. 2016, 2, 131-138.

(5) Ley, S. V.; Fitzpatrick, D. E.; Ingham, R. J.; Myers, R. M. Organic Synthesis: March of the Machines. Angew. Chem. Int. Ed. 2015, 54, 3449-3464.

(6) Shukla, C. A.; Kulkarni, A. A. Automating Multistep Flow Synthesis: Approach and Challenges in Integrating Chemistry, Machines and Logic. Beilstein J. Org. Chem. 2017, 13, 960-987.

(7) Fitzpatrick, D. E.; Ley, S. V. Engineering Chemistry for the Future of Chemical Synthesis. Tetrahedron 2018, 74, 3087-3100.

(8) Perera, D.; Tucker, J. W.; Brahmbhatt, S.; Helal, C. J.; Chong, A.; Farrell, W.; Richardson, P.; Sach, N. W. A Platform for Automated Nanomole-Scale Reaction Screening and Micromole-Scale Synthesis in Flow. Science 2018, 359, 429-434. 
(9) Trobe, M.; Burke, M. D. The Molecular Industrial Revolution: Automated Synthesis of Small Molecules. Angew. Chem. Int. Ed. 2018, 57, 4192-4214.

(10) Coley, C. W.; Green, W. H.; Jensen, K. F. Machine Learning in Computer-Aided Synthesis Planning. Acc. Chem. Res. 2018, 51, 1281-1289.

(11) Ley, S. V. The Engineering of Chemical Synthesis: Humans and Machines Working in Harmony. Angew. Chem. Int. Ed. 2018, 57, 5182-5183.

(12) Moore, J. S.; Jensen, K. F., Automation in Microreactor Systems. In Microreactors in Organic Chemistry and Catalysis, Wirth, T., Ed. Wiley-VCH, 2013; pp 81-100.

(13) Rasheed, M.; Wirth, T. Intelligent Microflow: Development of Self-Optimizing Reaction Systems. Angew. Chem. Int. Ed. 2011, 50, 357-358.

(14) Fabry, D. C.; Sugiono, E.; Rueping, M. Self-Optimizing Reactor Systems: Algorithms, On-line Analytics, Setups, and Strategies for Accelerating Continuous Flow Process Optimization. Isr. J. Chem. 2014, 54, 341-350.

(15) Reizman, B. J.; Jensen, K. F. Feedback in Flow for Accelerated Reaction Development. Acc. Chem. Res. 2016, 49, 1786-1796.

(16) Sans, V.; Cronin, L. Towards Dial-a-Molecule by Integrating Continuous Flow, Analytics and Self-Optimisation. Chem. Soc. Rev. 2016, 45, 2032-2043.

(17) Fabry, D. C.; Sugiono, E.; Rueping, M. Online Monitoring and Analysis for Autonomous Continuous Flow Self-Optimizing Reactor Systems. React. Chem. Eng. 2016, 1, 129-133.

(18) Wegner, J.; Ceylan, S.; Kirschning, A. Ten Key Issues in Modern Flow Chemistry. Chem. Commun. 2011, 47, 4583-4592.

(19) Ley, S. V. On Being Green: Can Flow Chemistry Help? Chem. Rec. 2012, 12, 378-390.

(20) Vaccaro, L.; Lanari, D.; Marrocchi, A.; Strappaveccia, G. Flow Approaches Towards Sustainability. Green Chem. 2014, 16, 3680-3704.

(21) Gutmann, B.; Cantillo, D.; Kappe, C. O. Continuous-Flow Technology-A Tool for the Safe Manufacturing of Active Pharmaceutical Ingredients. Angew. Chem. Int. Ed. 2015, 54, 6688-6728.

(22) Movsisyan, M.; Delbeke, E. I. P.; Berton, J. K. E. T.; Battilocchio, C.; Ley, S. V.; Stevens, C. V. Taming Hazardous Chemistry by Continuous Flow Technology. Chem. Soc. Rev. 2016, 45, 4892-4928.

(23) Plutschack, M. B.; Pieber, B.; Gilmore, K.; Seeberger, P. H. The Hitchhiker's Guide to Flow Chemistry. Chem. Rev. 2017, 117, 11796-11893.

(24) Krishnadasan, S.; Brown, R. J. C.; deMello, A. J.; deMello, J. C. Intelligent Routes to The Controlled Synthesis of Nanoparticles. Lab Chip 2007, 7, 1434-1441. 
(25) Walker, B. E.; Bannock, J. H.; Nightingale, A. M.; deMello, J. C. Tuning Reaction Products by Constrained Optimisation. React. Chem. Eng. 2017, 2, 785-798.

(26) McMullen, J. P.; Jensen, K. F. An Automated Microfluidic System for Online Optimization in Chemical Synthesis. Org. Process Res. Dev. 2010, 14, 1169-1176.

(27) McMullen, J. P.; Stone, M. T.; Buchwald, S. L.; Jensen, K. F. An Integrated Microreactor System for Self-Optimization of a Heck Reaction: From Micro- to Mesoscale Flow Systems. Angew. Chem. Int. Ed. 2010, 49, 7076-7080.

(28) Moore, J. S.; Jensen, K. F. Automated Multitrajectory Method for Reaction Optimization in a Microfluidic System using Online IR Analysis. Org. Process Res. Dev. 2012, 16, 14091415.

(29) Reizman, B. J.; Jensen, K. F. Simultaneous Solvent Screening and Reaction Optimization in Microliter Slugs. Chem. Commun. 2015, 51, 13290-13293.

(30) Reizman, B. J.; Wang, Y.-M.; Buchwald, S. L.; Jensen, K. F. Suzuki-Miyaura CrossCoupling Optimization Enabled by Automated Feedback. React. Chem. Eng. 2016, 1, 658666.

(31) Hsieh, H.-W.; Coley, C. W.; Baumgartner, L. M.; Jensen, K. F.; Robinson, R. I. Photoredox Iridium-Nickel Dual-Catalyzed Decarboxylative Arylation Cross-Coupling: From Batch to Continuous Flow via Self-Optimizing Segmented Flow Reactor. Org. Process Res. Dev. 2018, 22, 542-550.

(32) Bourne, R. A.; Skilton, R. A.; Parrott, A. J.; Irvine, D. J.; Poliakoff, M. Adaptive Process Optimization for Continuous Methylation of Alcohols in Supercritical Carbon Dioxide. Org. Process Res. Dev. 2011, 15, 932-938.

(33) Parrott, A. J.; Bourne, R. A.; Akien, G. R.; Irvine, D. J.; Poliakoff, M. Self-Optimizing Continuous Reactions in Supercritical Carbon Dioxide. Angew. Chem. Int. Ed. 2011, 50, 3788-3792.

(34) Jumbam, D. N.; Skilton, R. A.; Parrott, A. J.; Bourne, R. A.; Poliakoff, M. The Effect of Self-Optimisation Targets on the Methylation of Alcohols Using Dimethyl Carbonate in Supercritical CO2. J. Flow Chem. 2012, 2, 24-27.

(35) Amara, Z.; Streng, E. S.; Skilton, R. A.; Jin, J.; George, M. W.; Poliakoff, M. Automated Serendipity with Self-Optimizing Continuous-Flow Reactors. Eur. J. Org. Chem. 2015, 61416145.

(36) Houben, C.; Peremezhney, N.; Zubov, A.; Kosek, J.; Lapkin, A. A. Closed-Loop Multitarget Optimization for Discovery of New Emulsion Polymerization Recipes. Org. Process Res. Dev. 2015, 19, 1049-1053. 
(37) Echtermeyer, A.; Amar, Y.; Zakrzewski, J.; Lapkin, A. Self-Optimisation and ModelBased Design of Experiments for Developing a $\mathrm{C}-\mathrm{H}$ Activation Flow Process. Beilstein J. Org. Chem. 2017, 13, 150-163.

(38) Sans, V.; Porwol, L.; Dragone, V.; Cronin, L. A Self Optimizing Synthetic Organic Reactor System Using Real-Time In-Line NMR Spectroscopy. Chem. Sci. 2015, 6, 12581264.

(39) Fitzpatrick, D. E.; Battilocchio, C.; Ley, S. V. A Novel Internet-Based Reaction Monitoring, Control and Autonomous Self-Optimization Platform for Chemical Synthesis. Org. Process Res. Dev. 2016, 20, 386-394.

(40) Poscharny, K.; Fabry, D. C.; Heddrich, S.; Sugiono, E.; Liauw, M. A.; Rueping, M. Machine Assisted Reaction Optimization: A self-Optimizing Reactor System for ContinuousFlow Photochemical Reactions. Tetrahedron 2018, 74, 3171-3175.

(41) Holmes, N.; Akien, G. R.; Savage, R. J. D.; Stanetty, C.; Baxendale, I. R.; Blacker, A. J.; Taylor, B. A.; Woodward, R. L.; Meadows, R. E.; Bourne, R. A. Online Quantitative Mass Spectrometry for the Rapid Adaptive Optimisation of Automated Flow Reactors. React. Chem. Eng. 2016, 1, 96-100.

(42) Holmes, N.; Akien, G. R.; Blacker, A. J.; Woodward, R. L.; Meadows, R. E.; Bourne, R. A. Self-Optimisation of the Final Stage in the Synthesis of EGFR Kinase Inhibitor AZD9291 Using an Automated Flow Reactor. React. Chem. Eng. 2016, 1, 366-371.

(43) Skilton, R. A.; Parrott, A. J.; George, M. W.; Poliakoff, M.; Bourne, R. A. Real-Time Feedback Control Using Online Attenuated Total Reflection Fourier Transform Infrared (ATR FT-IR) Spectroscopy for Continuous Flow Optimization and Process Knowledge. Appl. Spectrosc. 2013, 67, 1127-1131.

(44) Jeraal, M. I.; Holmes, N.; Akien, G. R.; Bourne, R. A. Enhanced Process Development Using Automated Continuous Reactors by Self-Optimisation Algorithms and Statistical Empirical Modelling. Tetrahedron 2018, 74, 3158-3164.

(45) Oger, N.; Le Grognec, E.; Felpin, F.-X. Continuous-Flow Heck-Matsuda Reaction: Homogeneous versus Heterogeneous Palladium Catalysts. J. Org. Chem. 2014, 79, 82558262.

(46) Oger, N.; Le Grognec, E.; Felpin, F.-X. Handling Diazonium Salts in Flow for Organic and Material Chemistry. Org. Chem. Front. 2015, 2, 590-614.

(47) Picard, B.; Gouilleux, B.; Lebleu, T.; Maddaluno, J.; Chataigner, I.; Penhoat, M.; Felpin, F.-X.; Giraudeau, P.; Legros, J. Oxidative Neutralization of Mustard-Gas Simulants in an On- 
Board Flow Device with In-Line NMR Monitoring. Angew. Chem. Int. Ed. 2017, 56, 75687572.

(48) Cortés-Borda, D.; Kutonova, K. V.; Jamet, C.; Trusova, M. E.; Zammattio, F.; Truchet, C.; Rodriguez-Zubiri, M.; Felpin, F.-X. Optimizing the Heck-Matsuda Reaction in Flow with a Constraint-Adapted Direct Search Algorithm. Org. Process Res. Dev. 2016, 20, 1979-1987.

(49) Chapman, O. L.; Engel, M. R.; Springer, J. P.; Clardy, J. C. Total Synthesis of Carpanone. J. Am. Chem. Soc. 1971, 93, 6696-6698.

(50) Baxendale, I. R.; Lee, A.-L.; Ley, S. V. A Concise Synthesis of Carpanone Using SolidSupported Reagents and Scavengers. J. Chem. Soc., Perkin Trans. 1 2002, 1850-1857.

(51) Constantin, M.-A.; Conrad, J.; Merişor, E.; Koschorreck, K.; Urlacher, V. B.; Beifuss, U. Oxidative Dimerization of (E)- and (Z)-2-Propenylsesamol with O2 in the Presence and Absence of Laccases and Other Catalysts: Selective Formation of Carpanones and Benzopyrans under Different Reaction Conditions. J. Org. Chem. 2012, 77, 4528-4543.

(52) Razzaq, T.; Glasnov, T. N.; Kappe, C. O. Accessing Novel Process Windows in a HighTemperature/Pressure Capillary Flow Reactor. Chem. Eng. Technol. 2009, 32, 1702-1716.

(53) Daniels, R. N.; Fadeyi, O. O.; Lindsley, C. W. A New Catalytic Cu(II)/Sparteine Oxidant System for $\beta, \beta$-Phenolic Couplings of Styrenyl Phenols: Synthesis of Carpanone and Unnatural Analogs. Org. Lett. 2008, 10, 4097-4100.

(54) Fadeyi, O. O.; Nathan Daniels, R.; DeGuire, S. M.; Lindsley, C. W. Total Synthesis of Polemannones B and C. Tetrahedron Lett. 2009, 50, 3084-3087.

(55) Liron, F.; Fontana, F.; Zirimwabagabo, J.-O.; Prestat, G.; Rajabi, J.; Rosa, C. L.; Poli, G. A New Cross-Coupling-Based Synthesis of Carpanone. Org. Lett. 2009, 11, 4378-4381.

(56) Clemens, M.; Sonja, H.; Stefan, K. Stopping the Babylonian Confusion: An Updated Nomenclature for Process Analyzers in PAT Applications. Chem. Ing. Tech. 2016, 88, 694697.

(57) Singh, K.; Blümich, B. NMR Spectroscopy with Compact Instruments. TrAC, Trends Anal. Chem. 2016, 83, 12-26.

(58) Giraudeau, P.; Felpin, F.-X. Flow Reactors Integrated with In-Line Monitoring Using Benchtop NMR Spectroscopy. React. Chem. Eng. 2018, 3, 399-413.

(59) Gouilleux, B.; Charrier, B.; Danieli, E.; Dumez, J.-N.; Akoka, S.; Felpin, F.-X.; Rodriguez-Zubiri, M.; Giraudeau, P. Real-Time Reaction Monitoring by Ultrafast 2D NMR on a Benchtop Spectrometer. Analyst 2015, 140, 7854-7858.

(60) Gouilleux, B.; Charrier, B.; Akoka, S.; Giraudeau, P. Gradient-Based Solvent Suppression Methods on a Benchtop Spectrometer. Magn. Reson. Chem. 2017, 55, 91-98. 
(61) Gouilleux, B.; Charrier, B.; Akoka, S.; Felpin, F.-X.; Rodriguez-Zubiri, M.; Giraudeau, P. Ultrafast 2D NMR on a Benchtop Spectrometer: Applications and Perspectives. Trends Analyt. Chem. 2016, 83, 65-75.

(62) Nelder, J. A.; Mead, R. A Simplex-Method for Function Minimization. Comput. J. 1965, 7, 308-313.

(63) Kiefer, J. Sequential Minimax Search for a Maximum. Proc. Am. Math. Soc. 1953, 4, 502-506.

(64) Shahbazali, E.; Noël, T.; Hessel, V. Photo-Claisen Rearrangement of Allyl Phenyl Ether in Microflow: Influence of Phenyl Core Substituents and Vision on Orthogonality. J. Flow Chem. 2016, 6, 252-259.

(65) Escribà-Gelonch, M.; Shahbazali, E.; Honing, M.; Hessel, V. Quality-In(Process)Line (QuIProLi) Process Intensification for a Micro-Flow UV-Photo Synthesis Enabled by Online UHPLC Analysis. Tetrahedron 2018, 74, 3143-3151.

(66) Bochicchio, A.; Cefola, R.; Choppin, S.; Colobert, F.; Di Noia, M. A.; Funicello, M.; Hanquet, G.; Pisano, I.; Todisco, S.; Chiummiento, L. Selective Claisen Rearrangement and Iodination for the Synthesis of Polyoxygenated Allyl Phenol Derivatives. Tetrahedron Lett. 2016, 57, 4053-4055.

(67) Han, X.; Armstrong, D. W. Using Geminal Dicationic Ionic Liquids as Solvents for High-Temperature Organic Reactions. Org. Lett. 2005, 7, 4205-4208.

(68) Razzaq, T.; Glasnov, T. N.; Kappe, C. O. Continuous-Flow Microreactor Chemistry under High-Temperature/Pressure Conditions. Eur. J. Org. Chem. 2009, 1321-1325.

(69) Bernal, J. M.; Lozano, P.; Garcia-Verdugo, E.; Burguete, M. I.; Sanchez-Gomez, G.; Lopez-Lopez, G.; Pucheault, M.; Vaultier, M.; Luis, S. V. Supercritical Synthesis of Biodiesel. Molecules 2012, 17, 8696-8719.

(70) Cantillo, D.; Kappe, C. O. Direct Preparation of Nitriles from Carboxylic Acids in Continuous Flow. J. Org. Chem. 2013, 78, 10567-10571.

(71) Adeyemi, A.; Bergman, J.; Brånalt, J.; Sävmarker, J.; Larhed, M. Continuous Flow Synthesis under High-Temperature/High-Pressure Conditions Using a Resistively Heated Flow Reactor. Org. Process Res. Dev. 2017, 21, 947-955.

(72) Gutmann, B. The Development of High-Temperature/High-Pressure Flow Chemistry A Tribute to the Pioneering Studies of Jürgen O. Metzger. J. Flow Chem. 2017, 7, 1-3.

(73) Tsoung, J.; Wang, Y.; Djuric, S. W. Expedient Diels-Alder Cycloadditions with OrthoQuinodimethanes in a High Temperature/Pressure Flow Reactor. React. Chem. Eng. 2017, 2, 458-461. 
(74) Lindsley, C. W.; Chan, L. K.; Goess, B. C.; Joseph, R.; Shair, M. D. Solid-Phase Biomimetic Synthesis of Carpanone-like Molecules. J. Am. Chem. Soc. 1999, 122, 422-423.

(75) Goess, B. C.; Hannoush, R. N.; Chan, L. K.; Kirchhausen, T.; Shair, M. D. Synthesis of a 10,000-Membered Library of Molecules Resembling Carpanone and Discovery of Vesicular Traffic Inhibitors. J. Am. Chem. Soc. 2006, 128, 5391-5403.

(76) Matsumoto, M.; Kuroda, K. Transition Metal(ii) Schiff's Base Complexes Catalyzed Oxidation of trans-2-(1-propenyl)-4,5-methylenedioxyphenol to Carpanone by Molecular Oxygen. Tetrahedron Lett. 1981, 22, 4437-4440.

(77) Baxendale, I. R.; Lee, A.-L.; Ley, S. V. A Concise Synthesis of the Natural Product Carpanone Using Solid-Supported Reagents and Scavengers. Synlett 2001, 1482-1484.

(78) Nishiyama, A.; Eto, H.; Terada, Y.; Iguchi, M.; Yamamura, S. Anodic Oxidation of Some Propenylphenols : Synthesis of Physiologically Active Neolignans. Chem. Pharm. Bull. 1983, 31, 2834-2844. 